\title{
Surface signature of Mediterranean water eddies in a long- term high-resolution simulation
}

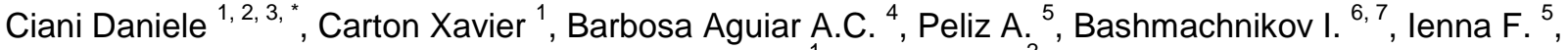 \\ Chapron Bertrand ${ }^{1}$, Santoleri R. ${ }^{2}$
}

${ }^{1}$ Laboratoire d'Océanographie Physique et Spatiale, Université de Brest, Ifremer, IRD, CNRS, Brest, France

${ }^{2}$ Consiglio Nazionale delle Ricerche, Istituto di Scienze dell'Atmosfera e del Clima (CNR-ISAC), Rome, Italy

${ }^{3}$ Collecte Localisation Satellites (CLS), Ramonville-St-Agne, France

${ }^{4}$ Met Office, Fitzroy Road, Exeter EX1 3PB, United Kingdom

${ }^{5}$ Instituto Dom Luiz, Faculdade de Ciências da Universidade de Lisboa, Lisbon, Portugal

${ }^{6}$ Institute of Earth Sciences, St. Petersburg State University (SPbSU), St. Petersburg, Russia

${ }^{7}$ Nansen International Environmental and Remote Sensing Centre (NIERSC), St. Petersburg, Russia

* Corresponding author : Daniele Ciani, email address : daniele.ciani@artov.isac.cnr.it

\begin{abstract}
:
We study the surface signatures of Mediterranean water eddies (Meddies) in the context of a regional, primitive equations model simulation (using the Regional Oceanic Modeling System, ROMS). This model simulation was previously performed to study the mean characteristics and pathways of Meddies during their evolution in the Atlantic Ocean. The advantage of our approach is to take into account different physical mechanisms acting on the evolution of Meddies and their surface signature, having full information on the 3D distribution of all physical variables of interest. The evolution of around 90 longlived Meddies (whose lifetimes exceeded one year) was investigated. In particular, their surface signature was determined in sea-surface height, temperature and salinity. The Meddy-induced anomalies were studied as a function of the Meddy structure and of the oceanic background. We show that the Meddies can generate positive anomalies in the elevation of the oceanic free-surface and that these anomalies are principally related to the Meddies potential vorticity structure at depth (around $1000 \mathrm{~m}$ below the sea-surface). On the contrary, the Meddies thermohaline surface signatures proved to be mostly dominated by local surface conditions and little correlated to the Meddy structure at depth. This work essentially points out that satellite altimetry is the most suitable approach to track subsurface vortices from observations of the sea-surface.
\end{abstract}




\section{Highlights}

- The surface signature of Meddies is studied in a high-resolution simulation. The aim is to evaluate a synergy between SSH/SST/SSS measurements for their tracking. SSH measurements are elected as the best strategy for tracking Meddies from space.

Keywords : Subsurface Anticyclones, Mediterranean water eddies, Satellite Detection 


\section{Introduction}

Mediterranean water eddies (Meddies) are mesoscale subsurface-intensified anticyclones generated by the outflow of Mediterranean water into the Atlantic Ocean. The first documented evidence of Meddies dates back to the late 60s, when rotating and anomalously high salinity structures were found in the proximity of the Strait of Gibraltar [Swallow (1969)].

The detailed three-dimensional structure of Meddies has been investigated via direct hydrological observation and numerical modeling [McDowell and Rossby (1978), Armi and Zenk (1984), Prater and Sanford (1994), Armi et al. (1989), Kase et al. (1989), Richardson et al. (1989), Pingree and Le Cann (1993b), Richardson et al. (2000a), Barbosa Aguiar et al. (2013), Bashmachnikov et al. (2015)]. They are generally identified as positive anomalies in temperature (up to $4^{\circ} \mathrm{C}$ ) and salinity (up to $1 \mathrm{PSU}$ ) with respect to the background ocean. Dynamically, such eddies have velocities mostly in the horizontal plane and they swirl at rates that can exceed $30 \mathrm{~cm} / \mathrm{s}$. Their radii range from 10 to around $70 \mathrm{~km}$ and their thicknesses range between 200 and $1200 \mathrm{~m}$, with a resulting aspect ratio $\mathcal{O}\left(10^{-2}\right)$ and Rossby numbers that can reach 0.3 [Aubert et al. (2012), Bashmachnikov et al. (2015)]. Hydrological observations confirmed that Meddy cores (if defined with respect to salinity) are mostly intensified at depths around $1000 \mathrm{~m}$, even though occurrences of cores at $700 \mathrm{~m}$ depth are possible [Pingree and Le Cann (1993a)].

Self-propagation, in addition to coupling with other eddies and/or regional currents makes Meddies non-stationary features, hence, able to propagate up to the Mid-Atlantic Ridge and even further [Käse and Zenk (1987), Colin de Verdière (1992), Morel (1995), Morel and McWilliams (1997), Carton et al. (2002), Carton et al. (2010)]. On average, a single Meddy can carry up to $10^{11}$ tons of salt [Bashmachnikov et al. (2015)], indicating that Meddies can efficiently redistribute the oceanic tracers (e.g. heat and salt) in the North Atlantic [Shapiro et al. (1995), Stephens and Marshall (1999), Richardson et al. (2000a)]. Thus, tracking Meddies is essential to evaluate heat and salt fluxes and distribution at thermocline level off the Iberian coast (up to $40-45^{\circ} \mathrm{W}$, western limit of the Mediterranean salinity tongue [Joyce (1981)]).

One of the most efficient Meddy-tracking strategies relies on the use of neutral buoyancy floats deployed at typical depths of the Mediterranean Outflow (MO hereinafter), or inside Meddy cores. Using this technique, Bower et al. (1997) detected ten Meddy-formation events, as well as the trajectory of several Meddies formed at Cape São Vicente and Estremadura Promontory. Similarly, the use of research vessels allows the detailed description of Meddy structures via CTD surveys, deployment of XBT, profilers, etc. [McDowell and Rossby (1978), Pingree and Le Cann (1993b), Richardson and Tychensky (1998), Tychensky and Carton (1998), Carton et al. (2002)]. The only disadvantage of these strategies is the lack of synopticity, allowing the analysis of only a few Meddies at a time. A rough 
calculation based on Meddy formation rate and mean lifetime, states that a snapshot of the North Atlantic would reveal around 30 Meddies in the basin [Richardson et al. (2000b)]. For these reasons, many attempts at detecting Meddies have relied on the synoptic information provided by satellite sensors.

Käse and Zenk (1987) hypothesized that Meddies could induce surface anticyclonic vorticity signals, and they confirmed this using satellite tracked drifters, whose trajectories were clearly driven by an underlying Meddy. Stammer et al. (1991), using Geosat altimetry data, found that Meddies can generate local bumps in sea-surface height (SSH hereinafter). This result was also confirmed by Bashmachnikov et al. (2009), who showed that the Meddyinduced sea-level anomalies are rather stable features in time and by Ienna et al. (2014), who tracked Meddies using satellite altimetric signals (AVISO gridded data) filtered at timescales larger than 6 months. Oliveira et al. (2000), combining fine-resolution seasurface temperature (SST hereinafter) and SSH measurements, confirmed that Meddies induce local positive anomalies in the elevation of the sea-surface. On the other hand, as corroborated by Bashmachnikov et al. (2013), Meddy signatures in SST strongly depend on the local thermal conditions at the sea-surface and are only detectable when SST gradients exist near an underlying Meddy.

All the works cited here were successful at tracking Meddies from space, though, at least in the initial stages of tracking, they relied on hydrological informations confirming the presence of a Meddy at depth.

The factors that can influence the surface expression of a Meddy in SSH are both due to the surrounding ocean and to the Meddy itself. Bashmachnikov and Carton (2012) and Ciani et al. (2015) state that an increase in Meddy radius, swirl velocity and thickness corresponds to larger sea-surface elevations. On the other hand, a larger depth of the Meddy core can diminish the eddy surface signal. Surface turbulent features, like surface eddies shed by fronts (e.g, the Azores front [Bashmachnikov et al. (2013), Bashmachnikov et al. (2014)]) can also perturb the anticyclonic signature of a Meddy and enhance the signal or make it disappear. Bashmachnikov and Carton (2012) found that stronger upper ocean stratifications can also reduce the SSH bumps related to an underlying Meddy. Most of the limitations in Meddy detectability via altimetry (an all-weather-available satellite technique) are due to interpolation, necessary to get two-dimensional maps from alongtrack data; $2 \mathrm{~cm}$ is the uncertainty for along-track data, while this value raises up to a maximum of $5 \mathrm{~cm}$ for gridded data [Fu and Cazenave (2000), Dibarboure et al. (2012)]. Larger Meddies can generate local SSH bumps around 10 to $15 \mathrm{~cm}$ [Bashmachnikov and Carton (2012)], though smaller eddies (even in idealized contexts) can have signatures below the $2 \mathrm{~cm}$ threshold [Ciani et al. (2015)]. The future SWOT satellite mission [Fu et al. (2009)], will directly provide global submesoscale-resolving and two-dimensional maps with 
uncertainties around $2 \mathrm{~cm}$. Moreover, one can wonder if the combination with present-day remotely sensed salinity (e.g. SMOS satellite) and temperature data could improve the Meddy detection from space or not.

All these considerations lead us to look for surface signatures of Mediterranean water eddies in a high-resolution realistic model, thoroughly described in Barbosa Aguiar et al. (2013). Using the model outputs, we colocated the surface signatures of a Meddy to its structure and displacement at depth. This was done for the SSH, SST and sea-surface salinity (SSS hereinafter) fields. The aim is to understand to which extent the combination of these informations can help us track a Meddy.

The paper is structured as follows: in section 2, the materials and methods of our investigations are presented, while section 3 contains the detailed analysis of the surface signature of three long lived Meddies in the model, each of them exhibiting a different pathway off the Strait of Gibraltar. Also, this section describes the overall behaviour of the surface signatures for the 90 longest lived Meddies in the model, with lifetimes ranging from 1 to more than 2 years (in section 3.2). Finally, the main conclusions and perspectives of our work are given in section 4 .

\section{Materials and Methods}

\subsection{The model}

The main characteristics of the model settings and outputs [Barbosa Aguiar et al. (2013)], are described here. The model is the primitive equations Regional Oceanic Modeling System (ROMS [Shchepetkin and McWilliams (2005)]). The modeled oceanic basin extends from $4.5^{\circ} \mathrm{W}$ to $20^{\circ} \mathrm{W}$ and from $32^{\circ} \mathrm{N}$ to $41^{\circ} \mathrm{N}$ in the zonal and meridional directions, respectively (see e.g. figure 1); with open boundary conditions given by a combination of radiation and flow-adaptive nudging towards climatological values, as described in Marchesiello et al. (2001). The grid horizontal spacing is around $3 \mathrm{~km}$ and the vertical discretization is given by 32 sigma levels. Integration in time is performed every $300 \mathrm{~s}$ and the outputs are averaged every 3 days. The model was run for 24 years (year zero is arbitrarily renamed as 2000) and a climatological atmospheric forcing was applied (COADS monthly climatologies [Da Silva et al. (1994)]). The simulation successfully reproduces the MO both in terms of transport and of temperature/salinity properties. Also, the time-mean maps of velocity field and of Eddy Kinetic Energy evaluated at 1000 m depth show patterns and intensities that are in agreement with previous studies [Bower et al. (2002), Peliz et al. (2007), Kida et al. (2008), Peliz et al. (2013)].

In this study, even though the model time will be used for convenience, one must be aware of the climatological nature of the forcing as well as the arbitrariness in the choice of the initial year. 
Finally, we point out that, in the aforementioned work, the Meddy trajectories have been simultaneously determined via an automatic eddy tracking software (ETS hereinafter [Nencioli et al. (2010)]) at the nominal depths of 600 and $1000 \mathrm{~m}$. The ETS is able to detect eddy centers and sizes from a bi-dimensional velocity field, respectively analyzing the geometrical distribution of the velocity vectors and the streamfunction field. Then, analyzing the time series of a velocity field, the ETS yields the path of the eddies centers, i.e., their trajectories.

In the results that follow, taking advantage of the a-priori known Meddy trajectories, we were able to colocate the Meddy instantaneous position to that of its surface expression (when present). This allowed us to describe the properties of the sea-surface anomalies induced by such eddies on oceanic surface elevation, temperature and salinity fields.

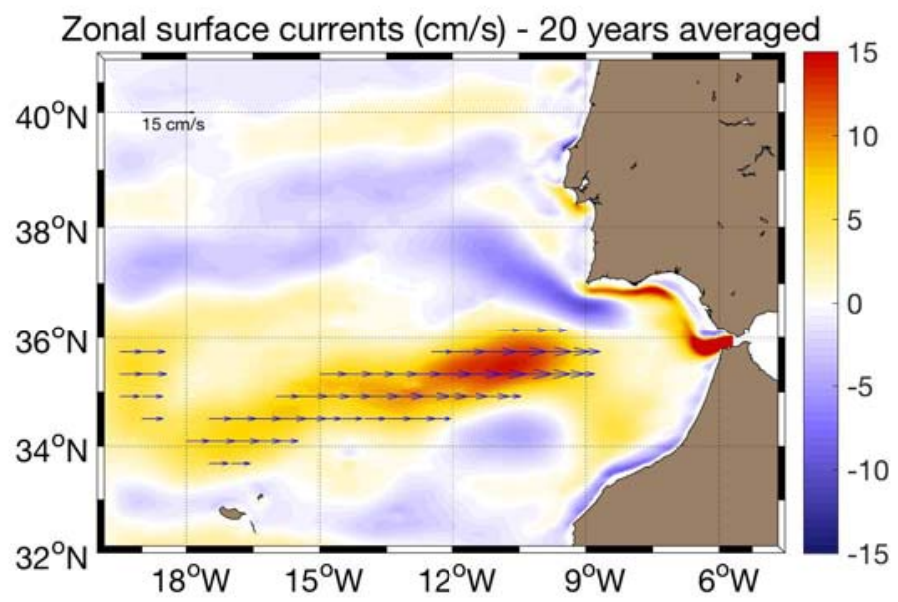

Figure 1: Climatological zonal surface currents (model-derived). The zonal band located between $34^{\circ} \mathrm{N}$ and $36^{\circ} \mathrm{N}$ is the footprint of the Azores front (also evidenced by the blue arrows).

\subsection{Definition of the Meddy surface signature}

We identify the Meddy dynamical surface signature via the Okubo-Weiss pattern (OW hereinafter) [Okubo (1970); Weiss (1991)] in the model surface layer. The OW-based detection method was preferred to the ETS as the latter can be difficult to use for tracking subsurface vortices in proximity of a turbulent surface-intensified structure as the Azores front.

The OW pattern is obtained from the model surface horizontal velocity field as $\mathrm{OW}=\sigma_{h}^{2}+$ $\sigma_{t}^{2}-\xi^{2}$, where $\sigma_{h}^{2}$ and $\sigma_{t}^{2}$ are the shear and strain deformation, respectively, and $\xi$ is the relative vorticity. In general, the $\mathrm{OW}$ gives the relative importance of deformation with 
respect to rotation and is characterized by negative values within vortices, i.e., where rotation dominates. The analysis of the OW field has also been used in past studies to track marine eddies (see e.g. Isern-Fontanet et al. (2003), Morrow et al. (2004) and Chelton et al. (2007)). For a given Meddy trajectory, we search for a minimum surface OW value spatially correlated with the position of the Meddy at depth, i.e., such point must lie within 1.5 Meddy radius from the Meddy center (the latest being independently detected at depth). Then, we take zonal and meridional sections of the OW surface field crossing the OW minimum. For every section, the horizontal extent of the signature is defined by the width of the "U-shaped" profile of the surface OW (see e.g. figure 2). As long as OW exhibits a negative sign, we assume it is associated to the Meddy anticyclonic vorticity. In figure 2, the center and horizontal extent of the Meddy surface signature are indicated by the red dots.

Finally, the Meddy signature is evaluated in SSH, SSS and SST linearly detrended fields. In particular, for every instant of the Meddy lifetime, the corresponding anomaly in sea-surface height will be defined using the information provided by the OW pattern. The anomaly is evaluated across the width of the OW profile and is given by the averaged SSH-differences between the center and the boundary of the Meddy dynamical signature. This is done for both the meridional and the zonal directions (see e.g. the blue radials in figure 2-middle panel). On the other hand, the Meddy-induced anomalies in SSS-SST fields are computed as the difference between the mean SSS-SST values in a "central" and a "peripheral region", respectively. Such regions are indicated in figure 2 (bottom panel): the central one (yellow circle) is the area extending from the center up to 0.25 radii of the Meddy dynamical signature, while, the peripheral one (blue annulus) extends from the edge up to 1.25 radii of the Meddy dynamical signature. This choice allows a better estimation of the anomalies associated with a flow convergence. Indeed, in those cases, four peripheral points would not be representative of the Meddy-induced anomaly with respect to the center of the signature.

In this study, we chose to deal with Meddies that could be successfully detected in the OW fields for at least $80 \%$ of their lifetime, except for the case of Meddy 120 (described in section 3.1.3). This choice assures that the long-term Meddies surface expression (including their seasonality) could be properly described.

\subsection{Meddy metrics and oceanic background parameters}

In order to characterize the behaviour of the Meddies surface signature, some properties of the Meddy, as well as of the surrounding ocean are derived along the eddy trajectory. We want to evaluate to what extent the seasonal and/or geographical variability of oceanic and Meddy parameters can affect the surface signature of such eddies. 

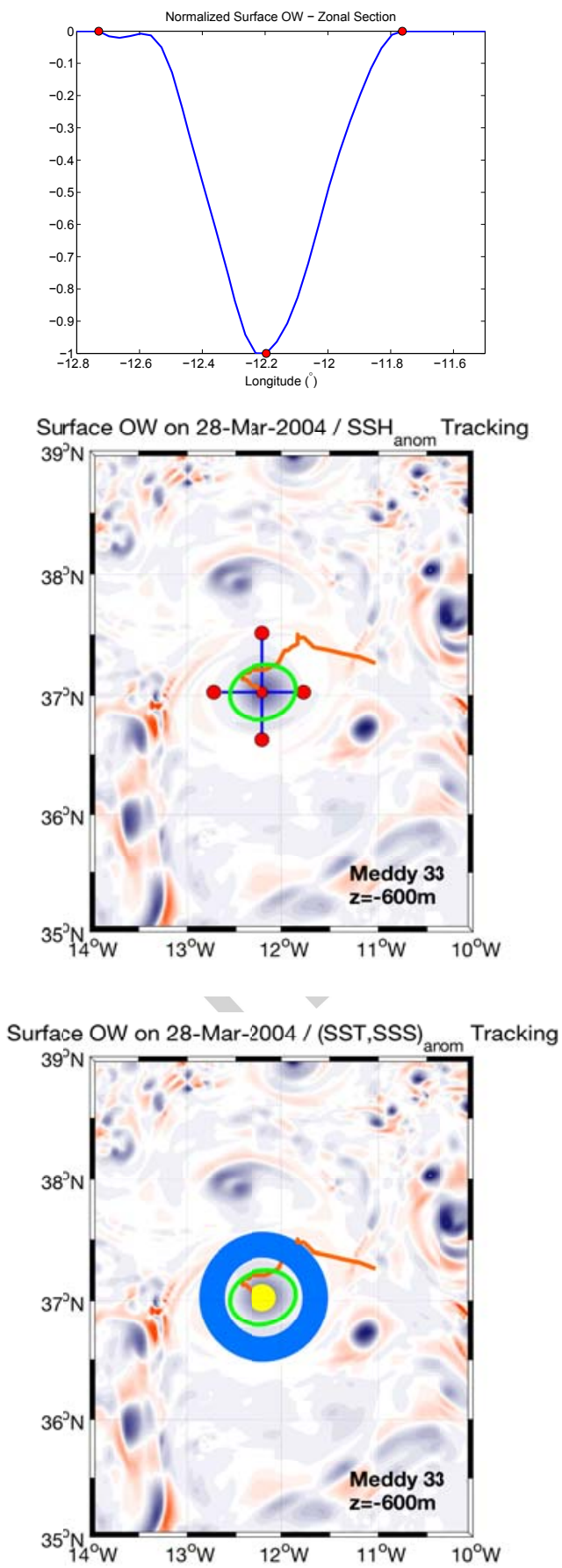

Figure 2: Surface signature associated to a Meddy. Top: zonal section (smoothed at $6 \mathrm{~km}$ ) of the Okubo Weiss (OW) surface field generated by the Meddy 33 on March 28th, 2004 (model time). Middle: surface OW field for a specific position of Meddy 33 (tracked at a depth of $600 \mathrm{~m}$, see also figure 3). The Meddy trajectory and its dynamical radius are indicated in orange and green, respectively (Eddy Tracking Software output, Nencioli et al. (2010)). The zonal and meridional sections of the surface $O W$ field are given by the blue radials. The red dots indicatte the center and limits of the radials. Bottom: surface OW field with tracking method for SST and SSS anomalies. The central and peripheral areas of the Meddy signature (at surface) are given by the yellow and blue regions, respectively. These areas are schematically highlighted to explain the SSS/SST anomalies tracking principle and are not in scale. 
This will be done for both the subsets of Meddies tracked (via the ETS) at $600 \mathrm{~m}$ and $1000 \mathrm{~m}$ depths. The along-trajectory properties are given in table 1 .

Table 1: Along-trajectory Meddy and background parameters. MLD : Mixed Layer Depth (m), $N$ : Brunt-Väisälä frequency $\left(\mathrm{s}^{-1}\right), \nabla h_{B}^{e}$ : bottom oceanic topography gradient $(\mathrm{m} / \mathrm{km})$, $U_{\text {clim }}$ : climatological zonal surface currents $(\mathrm{cm} / \mathrm{s}), S V:$ Swirl Velocity $(\mathrm{cm} / \mathrm{s})$, R: Radius $(\mathrm{km})$, Th: Thickness $(\mathrm{m}), \mathrm{D}$ : Depth $(\mathrm{m}), i$-EPVa: volume integrated potential vorticity anomaly $\left(m^{2} \cdot s^{-1}\right.$, $i$-Sa: volume integrated salinity anomaly $\left(P S U \cdot m^{3}\right), i$-Ta: volume integrated temperature anomaly $\left({ }^{\circ} \mathrm{C} \cdot \mathrm{m}^{3}\right)$.

\begin{tabular}{cccccccc}
\hline BACKGROUND & MLD & $N$ & $\nabla \mathrm{h}_{B}^{e}$ & $\mathrm{U}_{\text {clim }}$ & & & \\
MEDDY & $\mathrm{SV}$ & $\mathrm{R}$ & $\mathrm{Th}$ & $\mathrm{D}$ & $\mathrm{i}-\mathrm{EPVa}$ & $\mathrm{i}-\mathrm{Sa}$ & $\mathrm{i}-\mathrm{Ta}$ \\
\hline
\end{tabular}

The Meddy parameters are derived from the model in combination with the ETS outputs. The Meddy Depth (D) is computed from vertical salinity profiles through the position of the Meddy center, the latter being an output of the ETS. The depth of the eddy core is given by the position of the maximum salinity along the vertical within the $500-1500 \mathrm{~m}$ depth-range. This choice is justified by most of the earlier works based on hydrological data [McDowell and Rossby (1978), Käse and Zenk (1987), Pingree and Le Cann (1993a), Pingree and Le Cann (1993b), Richardson et al. (2000a), Bashmachnikov et al. (2015)] stating that Meddies are mostly intensified in the aforementioned depth-range. The Swirl Velocities (SV) and Radii (R) are both evaluated at the depth of the salinity core. Firstly, we compute the quantity $\mathrm{U}=\sqrt{u^{2}+v^{2}}$, where $\mathrm{u}$ and $\mathrm{v}$ are the zonal and meridional components of the currents, respectively. Then, we average the four maximum values of $U$ $\left(\mathrm{U}_{\max }\right)$ observed along two radial sections passing through the Meddy center and oriented meridionally and zonally. The four $\mathrm{U}_{\max }$ values are identified by the region where the $\mathrm{U}$ gradient, evaluated along the radial sections from the Meddy center towards its periphery, becomes zero for the first time. Hence, such radial sections also provide an information on the dynamical radius, which is defined here as the average distance between the Meddy center and the four positions of $\mathrm{U}_{\max }$. The Meddy Thickness (Th) is also evaluated using vertical salinity profiles passing through the eddy center. The vertical boundaries of the eddy are searched in the 200 to $2000 \mathrm{~m}$ depth-range. This choice allows one to neglect the salinity values associated with the oceanic surface layers, i.e., not related to the MO. Such bounds are defined as the uppermost point in which the vertical salinity gradient is positive and the lowermost in which such gradient is negative $(z$ increasing downward for the computation of the vertical gradient). In addition, such points must be characterized by a salinity anomaly $\Delta S \geq 0.1$ PSU. Notice that the salinity anomaly is defined with respect to a model-derived monthly climatological salinity. Finally, the i-Sa, i-Ta and i- 
EPVa, are the three-dimensional integrals of the salinity, temperature and Ertel potential vorticity (EPV hereinafter ${ }^{1}$ ) anomalies, respectively. Such integrals are computed within the Meddy volume, whose vertical bounds are given by the aforementioned salinity criterion. The Meddy lateral bounds, for each vertical level, are considered in the integral computation algorithm: only values exhibiting EPV, salinity and temperature anomalies (with respect to the monthly climatology) larger than $0.1 \cdot\left(10^{11}\right) \mathrm{m}^{-1} \mathrm{~s}^{-1}, 0.1$ PSU and 0.1 ${ }^{\circ} \mathrm{C}$ within two Meddy radii are taken into account, respectively. Notice that, although anticyclones generally have negative EPV cores, in this study we integrate the -EPV quantity by convention.

Regarding the oceanic background parameters, the depth of the Mixed Layer (MLD) is computed from vertical temperature profiles as described in Lorbacher et al. (2006), who defined the MLD as the first local maxima in the curvature, i.e. the second derivative, of the temperature (or density) vertical profiles.

$\mathbf{N}$ is the average Brunt-Väisälä frequency above the Meddy upper limit (i.e., from the Meddy top to the ocean surface). Hence, $\mathbf{N}$ will exhibit both a geographical and a seasonal variability, due to combined effect of the Meddy displacement and to the seasonal oscillations of the oceanic mixed layer depth.

The role of the oceanic bottom topography $\left(\nabla \mathbf{h}_{\mathbf{B}}^{\mathbf{e}}\right)$ is also investigated. The superscript $e$ indicates that such gradient accounts for the $e$-decay scale of the eddy properties with depth $H_{m}$ [Bashmachnikov et al. (2014)]. In particular, we compute the gradient of the along-trajectory bottom features, using (1) and (2):

$$
\begin{gathered}
\nabla h_{B}^{e}(t)=\frac{h_{t+1}-h_{t}}{s_{t+1}-s_{t}} \cdot e^{\frac{-\left|h_{t}-h_{0}\right|}{H_{m}}} \\
H_{m}=\frac{R f}{1.53 N_{b}}
\end{gathered}
$$

In (1) and (2), $h$ is the local elevation of the bottom topography, $s_{t+1}-s_{t}$ is the curvilinear distance between two Meddy successive positions, $h_{0}$ the depth of the Meddy core, $f$ is the local Coriolis parameter and $N_{b}$ is the mean Brunt-Väisälä frequency averaged between the Meddy lower bound and the oceanic bottom. This allows us to verify whether or not a bump or a depression in the oceanic bottom can modify the Meddy surface signature. The main topographic features in the region of study are given by the Horseshoe Seamount chain. The main seamounts have been schematically indicated in figure 3 .

${ }^{1} \mathrm{EPV}=\frac{1}{\rho}\left[\left(\partial_{x} v-\partial_{y} u+f\right) \partial_{z} \rho-\partial_{z} v \partial_{x} \rho+\partial_{z} u \partial_{y} \rho\right]$; where $\rho, u$ and $v$ are the seawater density, the zonal and the meridional component of the flow, respectively [Vallis (2006)]. 
Finally, the model-derived climatology of the zonal surface currents $\left(\mathbf{U}_{\text {clim }}\right)$ is also computed. This information gives an indication of the position of the Azores front in the model (see e.g. figure 1 and 3), allowing to evaluate whether the interaction between the Meddy surface signature and the front is destructive or not. In this study, we investigate the role of the Azores front as it is a major dynamical structure in the modeled region. It is an eastward zonal jet centred around $34^{\circ} \mathrm{N}$. It is generated via the $\beta$-plume mechanism, by the entrainment of surface Atlantic water-masses as the MO dense waters sink in the Gulf of Cadiz. Its intensity can exceed $10 \mathrm{~cm} \mathrm{~s}^{-1}$ and its horizontal and vertical extent are around $2^{\circ}$ and $1000 \mathrm{~m}$, respectively. The meandering of the Azores front is also responsible for the ejection of surface intensified eddies in the North Atlantic [Klein and Siedler (1989), Jia (2000), Özgökmen et al. (2001), Kida et al. (2008), Volkov and Fu (2010), Barbosa Aguiar et al. (2011)]. Hence, this jet can easily interact with Meddies (intensified around 1000 $\mathrm{m}$ below the sea-surface) as well as with their surface signatures. In our study, the mean position of the Azores front (in the model) will be also used to separate the region of study into the "Northern Basin" and the "Southern Basin", north and south of the front, respectively.

\section{Results}

In a first step, Meddies were classified into three groups, according to their lifetime (Group 1: Lifetime exceeding 2 years, Group 2: Lifetime comprised between 1 and 2 years, Group 3: Lifetime less than 1 year). In our work, we will focus on the Meddies of Group 1 and 2. This choice, though reducing the number of eddies that can be analyzed, allows us to investigate Meddies which travel over long distances in the Atlantic Ocean, hence, whose evolution is more likely to be influenced by geographical factors, seasonal effects or Meddy intrinsic variations than shorter-lived structures (lifetime $\mathcal{O}$ (month)). Indeed, the eddy parameters can significantly vary as the eddy drifts away from the Iberian coast [Armi et al. (1989), Barbosa Aguiar et al. (2013), Bashmachnikov et al. (2015)]. Moreover, environmental parameters (e.g, stratification, Mixed Layer Depth, etc.) also vary due to a combination of seasonal and geographical effects (since most Meddies drift southwestward). Such a choice proves useful if one wants to describe the long-term behaviour of the Meddies signatures (to help evaluating the possibility of a tracking via satellite sensors)

\subsection{Along-trajectory Meddy surface signature}

The trajectories of the eight longest-lived Meddies in the model during the 24 year period (lifetimes between 1.5 and 2.5 years) are given in figure 3. In this figure, each eddy is labeled after the ETS outputs and its initial and final positions are respectively indicated by a circle and a cross. Note that Meddies 68, 139 and 169 can be classified as "westward 
moving Meddies", since 98\%, 66\% and $100 \%$ of their trajectory respectively lies north of the Azores front (see e.g. figure 1 and 3). The other Meddies remain in the Northern Basin for less than $50 \%$ of their trajectory and they will be referred to as "southwestward moving Meddies".

In what follows, we present a comparative study of Meddies 33, 169 and 120. While Meddy 33 and 169 show pathways typical of most Meddies in the Atlantic Ocean [Barbosa Aguiar et al. (2013), Bower et al. (1997)], Meddy 120 exhibits a mostly southward and unusually looping trajectory. The implications of these different behaviours on the Meddies expression at the sea-surface will be discussed in detail.

\subsubsection{The case of a "southwestward moving Meddy" : Meddy 33}

Meddy 33 is the longest-living Meddy of Group 1 (lifetime $\simeq 2.5$ years). This eddy, like most of the subsurface-intensified anticyclones in the $\beta$-plane approximation, exhibits an equatorward trajectory [see e.g. Morel and McWilliams (1997)].

Firstly detected on January 1st, 2004 (model time) in the proximity of Gorringe Bank $\left(11^{\circ} \mathrm{W}, 37^{\circ} \mathrm{N}\right.$, see also fig. 3), it makes its way through the Horseshoe Seamount chain and, after crossing the Azores front during October 2004, it reaches the edge of the modeled domain (i.e., the so called sponge layer) on June 9th, 2006. The along-trajectory properties of the Meddy and background ocean are illustrated in figures 4 and 5 .

During the 2.5 years of evolution, our surface tracking indicates that the Meddy can generate a surface signature (in the OW fields) that extends horizontally between 0.2 and 2 eddy radii (figure 5-d). The induced SSH anomaly is always positive and has an overall decreasing linear trend of $2 \mathrm{~cm} /$ year. Its maximum value is around $7 \mathrm{~cm}$, as observed during April 2004. The SSH anomaly abruptly decreases around October 2004 and then keeps a fairly constant value ( $\simeq 1.5 \mathrm{~cm}$ ) up to the last Meddy tracked position (figures 4 -a and 5 -a). Several physical processes contributed to the evolution of this anomaly, as also indicated by figures 4, 5, 6 and table 3 .

From January to late March 2004, the SSH anomaly grows by about $1.7 \mathrm{~cm} / \mathrm{month}$. This initial positive trend results from the merger of Meddy 33 with a nearby Meddy, in correspondence of a deepening-phase of the mixed layer (MLD) (fig. 5-e). The merger event is shown in figure 6-left and its initial and final stages are respectively highlighted in figures 4-a and 5-a by the yellow diamonds and triangles (during January 2004). Moreover, this merger occurrence is corroborated by the corresponding positive trends in the Meddy integrated EPV, temperature and salinity anomalies as well as its swirl velocity and radius (respectively shown in figures 4-d,e,f and 5-g,h). This mechanism is confirmed by theoretical studies in the framework of the quasi-geostrophic theory, as well as observations of the real ocean [Bashmachnikov and Carton (2012), Bashmachnikov et al. (2015), Ciani et al. (2015), Ciani et al. (2016)]. Regarding the effects of the mixed layer depth (hence, the 


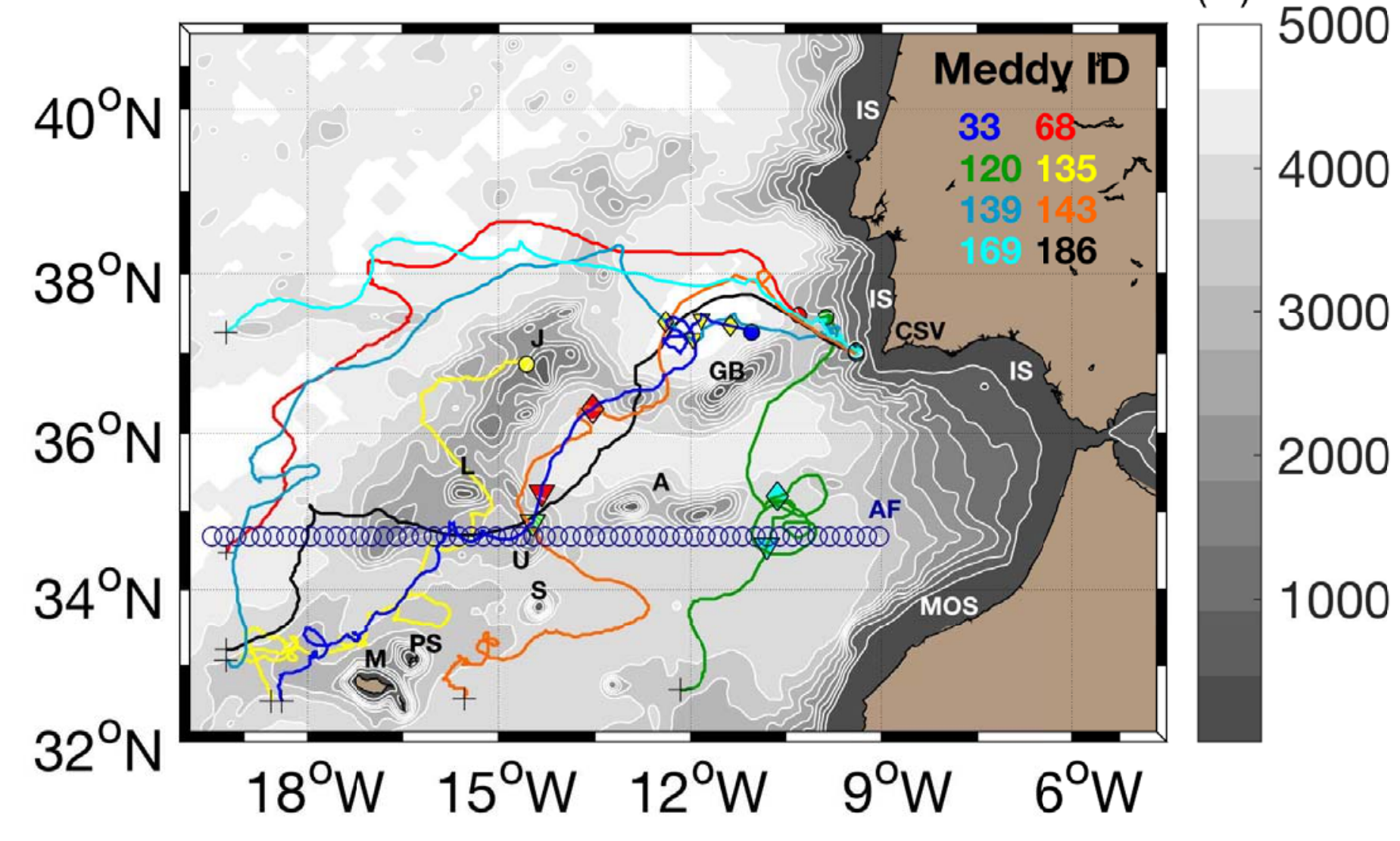

Figure 3: Trajectories of the longest-living Meddies in the simulation (1.5 years $<$ lifetime $<2.5$ years) over bathymetry. The Meddies trajectories are detected at both $600 \mathrm{~m}$ and 1000 $m$ depth. The Meddies are labeled after the automatic detection algorithm of Nencioli et al. (2010). The main topographic and dynamical features are labeled in capital letters over the bathymetry: A (Ampère seamount), GB (Gorringe Bank seamount), J (Josephine seamount), L (Lion seamount), S (Seine seamount), U (Unicorn seamount), MOS (Moroccan continental shelf), IS (Iberian continental shelf), $M$ (Madeira), PS (Porto Santo), CSV (Cape São Vicente), AF (mean axis of the Azores front in the simulation, giv). The diamonds and the downward pointing triangles along the trajectory of Meddy 33 and 120 are respectively commented in sections 3.1.1 and 3.1.3. The blue circles indicate the mean axis of the Azores front $(A F)$ in the simulation. 
Meddy 33
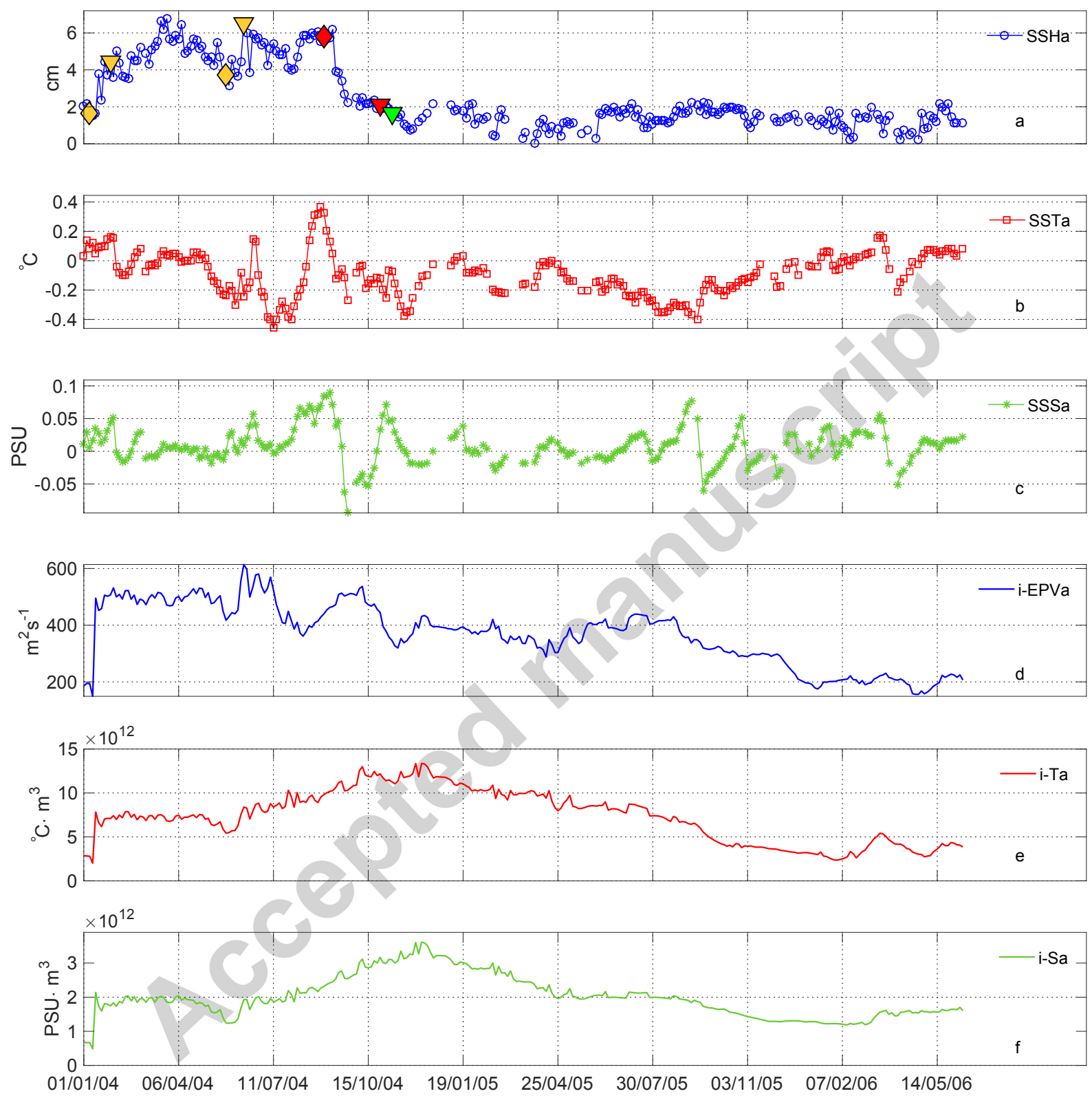

Figure 4: Surface signature and volume-integrated eddy parameters along the trajectory of Meddy 33 (see also Figure 3). a: SSHa (SSH anomaly, blue circles; the colour-filled downward pointing triangles and diamonds are commented in section 3.1.1), b: SSTa (SST anomaly, red squares), $c$ : SSSa (SSS anomaly, green stars), d: i-EPVa (integrated Ertel potential vorticity anomaly, blue), e: i-Ta (integrated temperature anomaly, red), $f: i$-Sa (integrated salinity anomaly, green). 


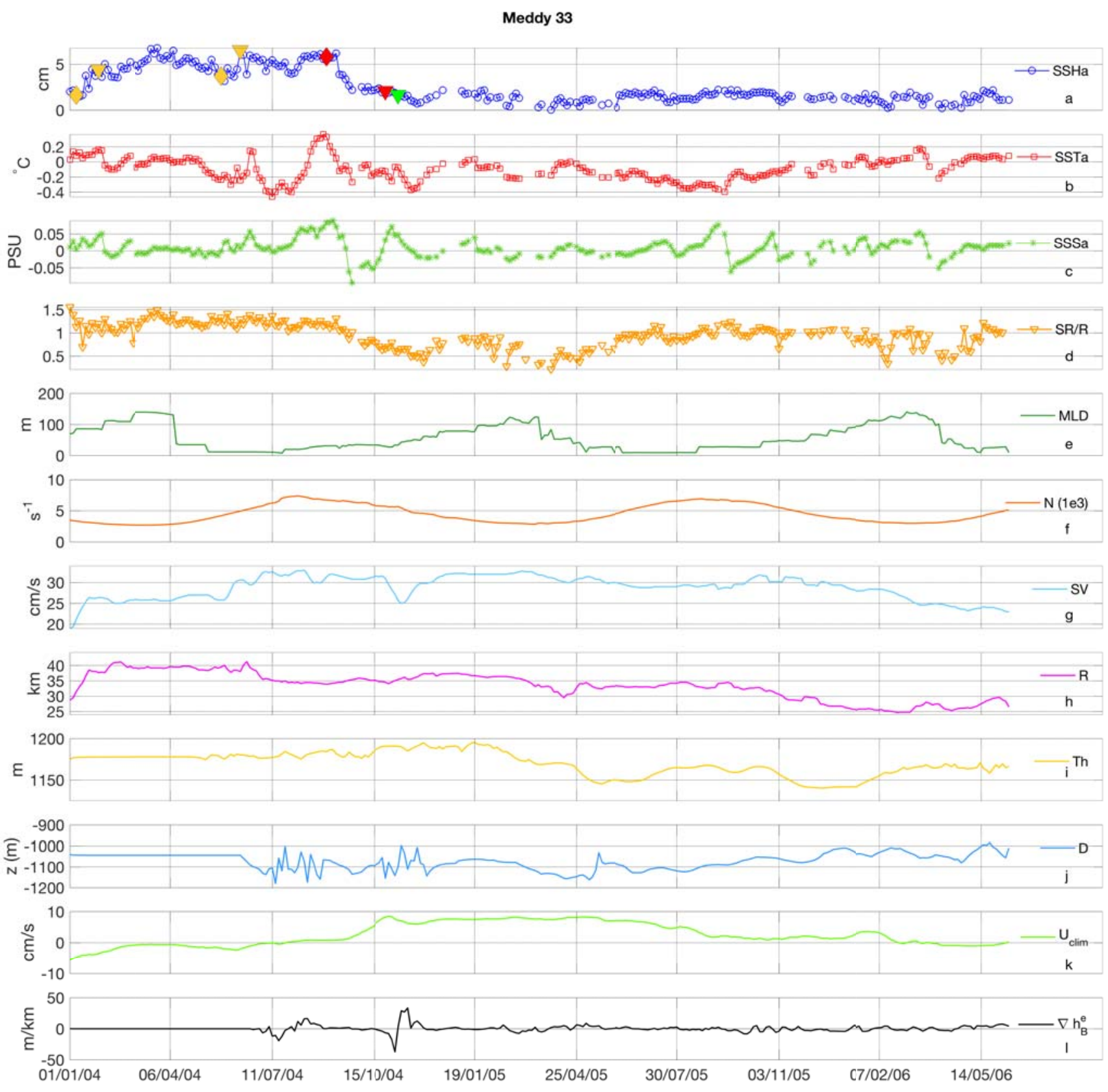

Figure 5: Surface signatures and Meddy/background properties along the trajectory of Meddy 33 (see also Figure 3). a: SSHa (SSH anomaly, blue circles; the colour-filled downward pointing triangles and diamonds are commented in section 3.1.1), b: SSTa (SST anomaly, red squares), $c$ : SSSa (SSS anomaly, green stars), $d: S R / R$ (Signature Radius over Meddy Radius, orange triangles), e: MLD (Mixed Layer Depth, green), $f: N$ (Brunt-Väisälä frequency, orange), ${ }_{g}^{14}{ }^{4} V$ (Meddy Swirl Velocity, cyan), $h: R$ (Meddy Radius, magenta), i: Th (Meddy thickness, yellow), $j: D$ (Meddy Depth, light blue), $k$ :

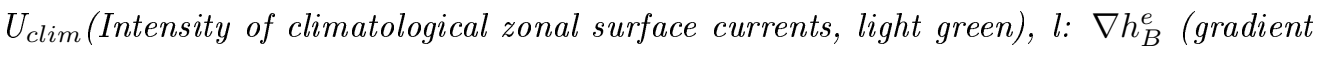
of oceanic bottom topography, black). 
upper ocean stratification), Bashmachnikov and Carton (2012) showed that the intensity of a Meddy-induced surface signature is inversely proportional to the Brunt Väisälä frequency (N, shown in figure 5-f) of the upper ocean. This is coherent with the evolution of SSH anomaly of Meddy 33, which exhibits a maximum value of $7 \mathrm{~cm}$ in correspondence of the first $\mathrm{N}$ local minimum, and a decrease in the April-July time window (when $\mathrm{N}$ increases again).

During late May/early June 2004, a second merger event (with a smaller Meddy compared to the case of January) generates the second peak in the SSH anomaly. Its initial and final stages are respectively given by the yellow diamonds and triangles through May/June 2004 in figures 4-a and 5-a. Figure 6-right shows the merger via horizontal sections of EPVa at the Meddy depth.

A third peak-phase in SSH anomaly is observed between July and October 2014. No merger events can be associated to this SSH anomaly. Indeed, the i-EPVa shows a local minimum in correspondence of the SSH anomaly peak. This minimum is due to lateral friction of the Meddy with the Gorringe Bank seamount, as also confirmed by the slight local decrease in swirl velocity during the Meddy/Seamount interaction (see figure 5-g). Instead, this peak was a case of indirect signature. Meddy 33 vertically aligned with a surface anticyclone (shedded by a meander of the Azores front), that enhanced the Meddy SSH anomaly (not shown). Such alignment progressively took place from September to early November 2004 and its duration is schematically highlighted by a red diamond (alignment) and triangle (end of the alignment) along the Meddy trajectory in figure 3 as well as in the SSH anomaly time series of figures 4-a and 5-a. This surface anticyclone had a dynamical radius around $35 \mathrm{~km}$, a swirl velocity around $30 \mathrm{~cm} / \mathrm{s}$ and extended vertically over $400 \mathrm{~m}$. According to Polvani (1991), given the characteristics of both the surface-anticyclone and the Meddy, vertical alignment is possible in this case, as both eddies have radii comparable with the Rossby deformation radius in the north-eastern Atlantic (i.e., where the alignment took place) [Chelton et al. (1998)]. Despite the duration of the alignment (around 2 months) the SSH anomaly started decreasing two weeks after the two eddies were aligned, due to the combined effect of the Azores front and of the Meddy/topography interactions. The Meddy 33, after crossing the Azores front, continued interacting with the Horseshoe Seamount chain, experiencing a series of lateral and bottom collisions. The combination of these two effects, plus the Meddy erosion itself (evidenced by the decreasing swirl velocity, radius and thickness in the second half of its lifetime, shown in figure 5-g,h,i) made the SSH anomaly decrease abruptly and maintain a fairly constant value up to the end of the Meddy trajectory (i.e. when it reached the sponge layer of the region of the modeled region).

It is worth noticing that, among the eddy/seamounts collisions, the one which mostly eroded Meddy 33 was not the lateral but the bottom collision (with the Unicorn Seamount 
in early November 2004), as evidenced by the i-EPVa field, the meridional section of the zonal swirl velocity across the Meddy (both shown in figure 7 ), the large value of the $\nabla \mathrm{h}_{B}^{e}$ time series (see figure 5-1) and by the corresponding local decrease of the swirl velocity (see figure 5-g). This event is again highlighted by a green triangle along the Meddy trajectory (figure 3) and in the SSH anomaly time series of figures 4-a and 5-a. Moreover, observing the i-EPVa, i-Ta and i-Sa behaviours in figure 4-d,e,f, one can clearly see how the overall decreasing trend of these quantities becomes evident in the aftermath of the Meddy bottom collision, in agreement with the results of Shapiro et al. (1995). In general, the behaviour of the i-Ta and i-Sa (for Meddy 33) can be explained as a combination of merger, hydrological properties of the surrounding ocean and the interaction of Meddy 33 with seamounts. Indeed, temperature and salinity of the surrounding ocean (at the Meddy depth) decrease all along the Meddy trajectory, as also confirmed by model-derived temperature and salinity climatologies (not shown). Hence, the i-Ta and i-Sa, initially growing because of merger, subsequently increase because the Meddy encounters fresher and cooler waters. Afterwards, when the Meddy starts interacting with seamounts, the i-Ta and i-Sa gradients become negative, most likely because of the water mass losses due to collisions, as well as the Meddy erosion due to diffusion.

Table 2: Mean properties of Meddy 33 surface signatures.

\begin{tabular}{|c|c|c|c|}
\hline MEDDY 33 & $S S H_{\text {anom }}$ & $S S T_{\text {anom }}$ & $S S S_{\text {anom }}$ \\
\hline Max & $7.2 \mathrm{~cm}$ & $0.34^{\circ} \mathrm{C}$ & $0.10 \mathrm{PSU}$ \\
Min & $0.10 \mathrm{~cm}$ & $-0.45^{\circ} \mathrm{C}$ & $-0.06 \mathrm{PSU}$ \\
$\% \geq 0$ & 100 & 35 & 64 \\
$\%<0$ & 0 & 65 & 36 \\
\hline
\end{tabular}

Table 3: Pearson's correlation coefficients $\left(R_{P}\right)$ between the Meddy 33 surface-signatures and the along-trajectory Meddy/background ocean characteristics. The largest values are highlighted in red.

\begin{tabular}{|c|c|c|c|c|c|c|c|c|c|c|}
\hline MEDDY 33-R & M Swirl & M Radius & M Thick. & MLD & N & U clim & $\boldsymbol{\nabla} \boldsymbol{h}_{\boldsymbol{B}}^{\boldsymbol{e}}$ & i-EPVa & i-Ta & i-Sa \\
\hline SSH $_{\text {anom }}$ & 0.69 & 0.55 & 0.59 & 0.04 & 0.13 & -0.53 & -0.02 & 0.71 & 0.15 & 0.15 \\
\hline MEDDY 33-R $_{P}$ & M Swirl & M Radius & M Thick. & MLD & N & U clim & $\boldsymbol{\nabla} \boldsymbol{h}_{\boldsymbol{B}}^{\boldsymbol{e}}$ & i-EPVa & i-Ta & i-Sa \\
\hline SST $_{\text {anom }}$ & -0.14 & -0.15 & 0.14 & -0.24 & 0.31 & 0.04 & 0.10 & -0.08 & 0.14 & 0.15 \\
\hline MEDDY 33-R $_{P}$ & M Swirl & M Radius & M Thick. & MLD & N & U clim & $\boldsymbol{\nabla} \boldsymbol{h}_{B}^{e}$ & i-EPVa & i-Ta & i-Sa \\
\hline SSS $_{\text {anom }}$ & 0.14 & -0.02 & 0.31 & 0.11 & 0.22 & -0.18 & 0.13 & 0.15 & 0.21 & 0.20 \\
\hline
\end{tabular}



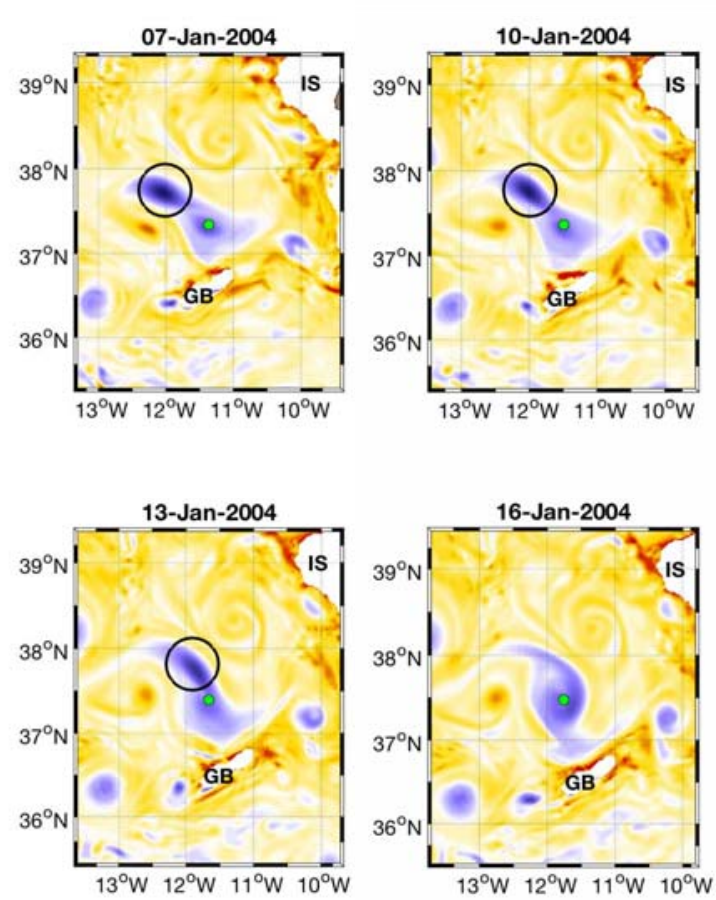
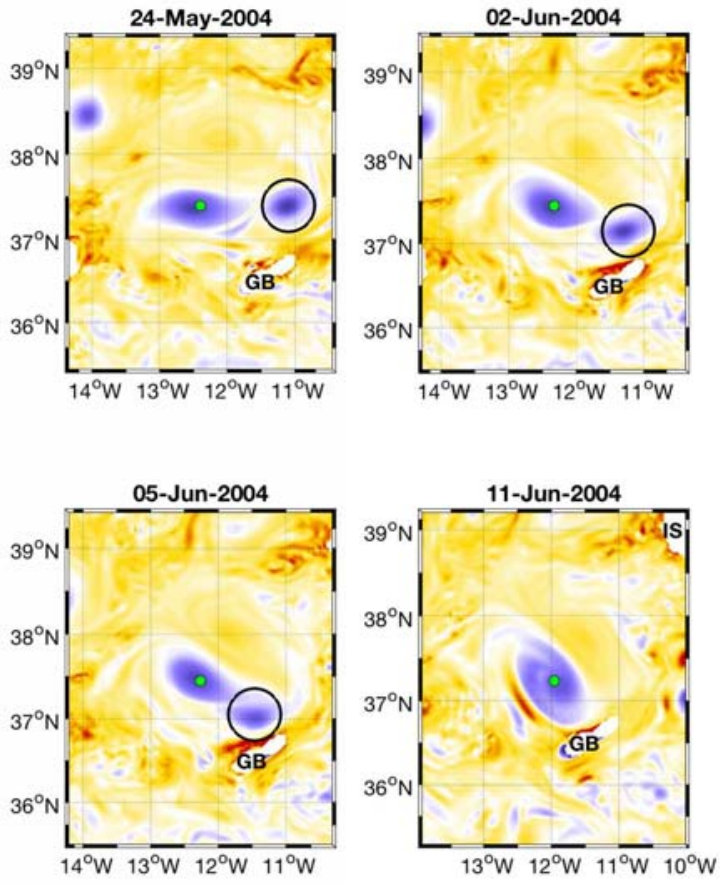

Figure 6: Merger of Meddy 33 with nearby Meddies (highlighted by the black circles). Left: first merger event, January 2004. Right: second merger event: May/June 2004. In both panels, merger is shown via horizontal sections of EPVa at the Meddy instantaneous depth $(z \simeq-1000 \mathrm{~m})$. The green dot indicates the instantaneous position of the Meddy center (ETS output). The white patches in the domain correspond to the Gorringe Bank Seamount and the Iberian continental shelf and are respectively labeled as GB and IS (see also figure 3). 

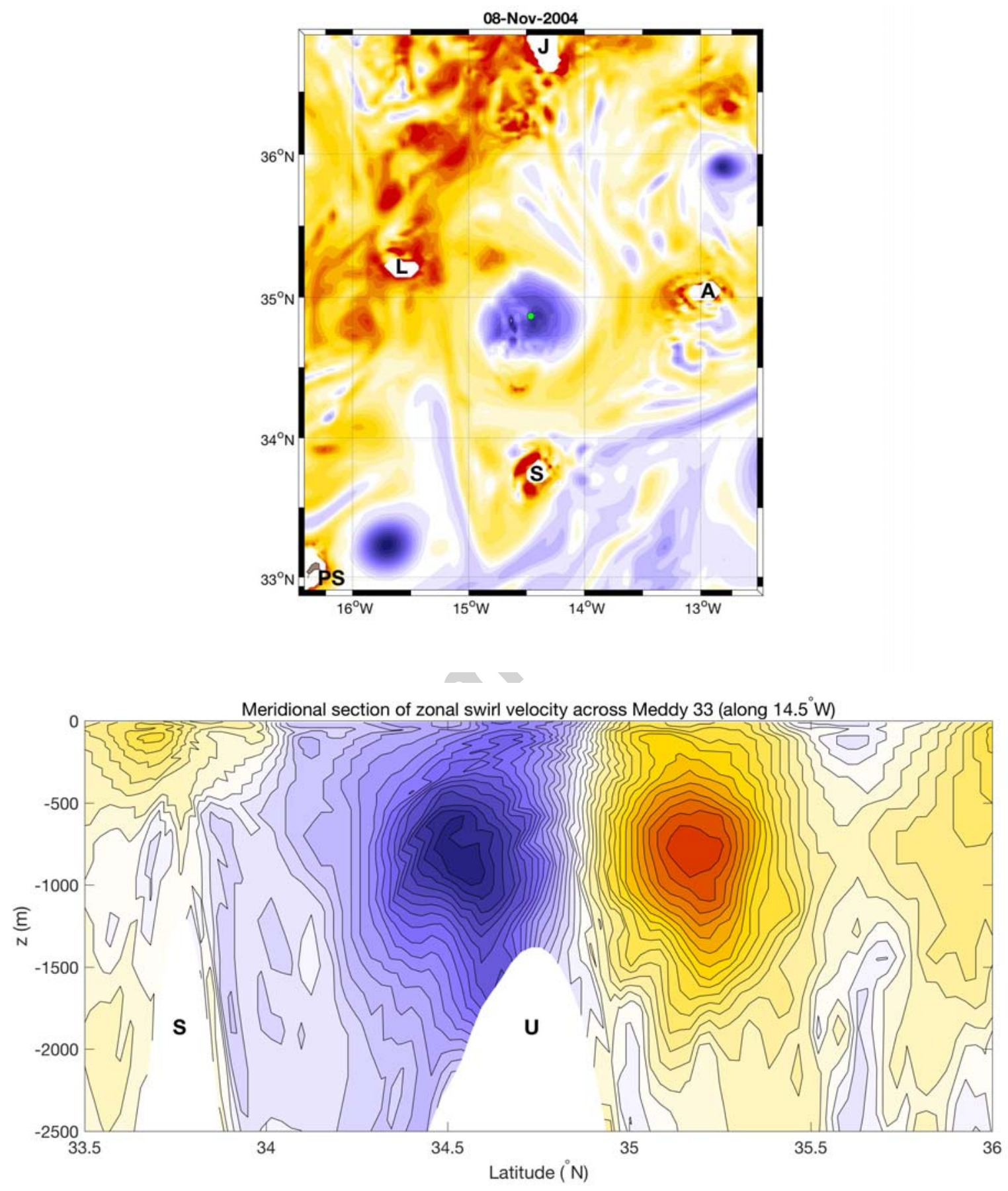

Figure 7: Bottom collision of Meddy 33 with the Unicorn seamount. Top panel: horizontal section of EPVa at a depth of $1000 \mathrm{~m}$ (the green dot indicates the istantaneous center of the Meddy, which is an ETS output). The white patches in the domain correspond to Josephine (J), Lion (L), Ampère (A), Seine (S) seamounts and the shelf around the Porto Santo Island (PS) (see also figure 3). Bottom panel: vertical cross section of the Meddy swirl velocity (zonal component), the darkest red and blue areas indicate a velocity field of $\pm 30 \mathrm{~cm} / \mathrm{s}$, respectivety. The white patches in the domain correspond to the vertical cross sections of the Seine (S) and Unicorn (U) seamounts. 
Unlike SSH anomaly, a trend for the behaviour of the SST anomaly and SSS anomaly cannot be defined. As the Meddy makes its way into the Atlantic, such anomalies can assume either positive or negative values around zero (see figures 4-b,c and 5-b,c), as also shown by the percentage of positive and negative SST and SSS anomalies listed in table 2. For Meddy 33, the negative SST anomalies slightly dominate the positive ones, observed during $65 \%$ of the Meddy lifetime, which is in line with the results of Bashmachnikov et al. (2013). Regardlees, the positive and negative peaks in the SST and SSS anomalies are seldom correlated with the evolution of the i-Ta and i-Sa. This suggests that the evolution of such anomalies is mostly driven by local surface conditions rather than from the presence of an underlying Meddy.

The general surface expression of Meddy 33 can also be summarized by means of table 3 , showing the Pearson's correlation coefficients [Fisher et al. (1946)] between each of the aforementioned anomalies and the time series of the Meddy/background characteristics. Note that, in table 3, all the correlation coefficients exhibit a significance level higher than $85 \%$ (except for the correlations between SSH-SSS-SST anom and $\nabla \mathrm{h}_{B}^{e}$, where it goes down to $60 \%$ ). The significance reaches $95 \%$ for the correlation between SSH anom and i-EPVa. The SSH anomalies are highly correlated with the variability of the Meddy swirl velocity and i-EPVa (the coefficients are around 0.7 in both cases). As stated previously, the Meddy radius and thickness are also correlated with the Meddy-induced SSH anomaly, showing coefficients larger than 0.5. A moderate anticorrelation $\left(\mathrm{R}_{P}=-0.53\right)$ is observed with respect to the along-trajectory time series of the surface climatological zonal currents $\mathrm{U}_{\text {clim }}$ (whose time series is given in figure $5-\mathrm{k}$ ). Recalling that the climatological surface currents allow us to evaluate the proximity of a Meddy with respect to the climatological imprint of the Azores front (see also figure 1), we can conclude that the SSH anomaly can be significantly degraded by the interaction with surface fronts (see also Herbette et al. (2004)). Indeed, as $\mathrm{U}_{\text {clim }}$ reaches its maximum value of about $10 \mathrm{~cm} / \mathrm{s}$ (maintained for several months of the Meddy evolution, as shown by figure 5), the SSH anomaly is damped by about $4 \mathrm{~cm}$. It is worth noticing that this happened 9 days before the Meddy went through the bottom collision with a seamount (shown in figure 7).

The along-trajectory depth of the oceanic mixed layer, and consequently, the average BruntVäisälä frequency above the Meddy (respectively shown in figure 5-e and 5-f) have an oscillatory character. This is due to their intrinsic seasonal variation during the 2.5 years of the Meddy evolution. During the first months of the Meddy evolution, N played a role in determining the Meddy surface expression, as shown by Bashmachnikov and Carton (2012). However, no significant correlations are found in the long term. This behaviour is due to the environment in which the Meddy evolved. In fact, Bashmachnikov and Carton (2012), in order to determine theoretical dependence of the Meddy surface signature with respect 
to the oceanic stratification, dealt with isolated features, neglecting Meddy/Meddy and Meddy/topography interactions, which is not the case for Meddy 33. The role of the alongtrajectory gradient of oceanic bottom topography $\nabla h_{B}^{e}$ has already been described. Even though it is not correlated with the overall SSH anomaly, we saw that local topographic features can interact with the Meddy and modify its three-dimensional structure, as well as its surface expression. Finally, the time series of i-Ta and i-Sa are not correlated with the Meddy-induced SSH anomaly, because $\mathrm{R}_{p}$ values never exceed 0.2. Also the correlation between the eddy-induced SST/SSS anomalies and the Meddy/background parameters never show values exceeding 0.3 . This result reinforces our previous statements on the role of local surface oceanic conditions in driving the Meddy thermohaline surface signature. A similar result was also found in Oliveira et al. (2000).

\subsubsection{Comparison with the longest-lived "westward moving Meddy": Meddy 169}

In this section, we compare Meddy 33 to one of the longest-lived westward moving Meddy: the Meddy 169 (lifetime $\simeq 1.5$ years, see also figure 3). Not only had Meddy 169 the peculiarity of an almost rectilinear and westward trajectory, but it also traveled far away from the main topographic features (except for the first days of its evolution, being firstly detected in proximity of Cape São Vicente, hence, close to the Iberian continental shelf). This property, excluding the interaction with other Meddies, makes Meddy 169 an isolated subsurface anticyclone (unlike Meddy 33, which underwent several interactions with seamounts and the Azores front). The along-trajectory Meddy and background oceanic properties are given in figures 8 and 9 . The SSH anomalies in figures 8 and 9 exhibit an average positive trend $(0.7 \mathrm{~cm} /$ month) for more than half of the Meddy's lifetime (from July 2019 to April 2020), and so it is for its i-EPVa $\left(43 \mathrm{~m}^{2} \mathrm{~s}^{-1} / \mathrm{month}\right.$, see figure 8-d), signature horizontal extent $(0.1 \mathrm{SR} / \mathrm{R})$, swirl velocity $\left(1.12 \mathrm{cms}^{-1} /\right.$ month $)$ and radius $(1.5$ $\mathrm{km} / \mathrm{month}$ ) (respectively shown in figure $9-\mathrm{d}, \mathrm{g}, \mathrm{h})$. On the other hand, the i-Ta and i-Sa increased up to the end of the Meddy trajectory, in November 2020 (see figure 8-e,f).

Meddy 169 was formed in a highly turbulent region, rich in mesoscale and submesoscale cyclonic and anticyclonic features (see e.g. figure 10). Its initial radius and swirl velocity are around $20 \mathrm{~km}$ and $20 \mathrm{~cm} / \mathrm{s}$, respectively. Afterwards, the Meddy started growing in size, rotate faster (as indicated by the average positive trend in swirl velocity, until April 2020), and its integrated EPVa, temperature and salinity anomalies also showed average positive trends (as shown in figures 8-d,e,f). This was due to a long series of merger events which fed the recently-formed Meddy (Bower et al. (1997) first identified Cape São Vicente as a Meddy generation site), modifying its initial structure and letting its surface signature grow both in size and intensity. In figure 10, the horizontal sections of EPVa show two merger events of Meddy 169 with nearby small-scale features in less than two weeks. The month of April 2020 is the approximate date when the i-EPVa reaches a plateau and the 
Meddy radius did not increase anymore (see figures 8-d and 9-h). We estimated that, by that date, Meddy 169 had drifted $615 \mathrm{~km}$ off the Iberian coast. Bashmachnikov et al. (2015) studied the mean properties of Meddies as a function of distance from the Iberian coast. They found that within a distance of $600 \mathrm{~km}$, the mean radii of Mediterranean water eddies monotonically increase and that this is principally due to merger. Indeed, Meddies are abundant in that distance range and the probability of merger events is high. The case of Meddy 169 is in agreement with this result, also because no evidence of merger was found after April 2020, making the Meddy an isolated feature (see also figure 10-right).

Once the series of merger events finished, the Meddy swirl velocity (in figure 9-g) stopped growing and maintained a fairly constant value. The radius and thickness, after a "plateauphase", only slightly increased and decreased, respectively (see figure 9-h,i). Such a behaviour is consistent with the results of Colin de Verdière (1992), who showed that the southward motion of Meddies can be due to their vertical shrinking and horizontal relaxation. Indeed, Meddy 169, while approaching the western boundary of the region of study, started exhibiting a southward displacement, switching from a latitude of $38.5^{\circ} \mathrm{N}$ to $37.3^{\circ} \mathrm{N}$ during the last 5 months of evolution (i.e. with a net southward velocity of around 0.65 $\mathrm{cm} / \mathrm{s}$ ). The SSH anomaly (as well as the horizontal extent of the Meddy signature in the OW fields) shows a decreasing trend of $-0.5 \mathrm{~cm} /$ month in the last months of evolution (see figure 9-a,d). In this context, where the eddy did not interact with topography (the $\nabla \mathrm{h}_{B}^{e}$ values are only significant in the early stages of the Meddy evolution (figure 9-1)) nor with other Meddies, the role of the oceanic upper stratification can become more significant in driving the surface expression. Indeed, the SSH anomaly (whose maximum value is observed when the MLD is deepest) starts decreasing when the oceanic mixed layer becomes shallower, i.e., when $\mathrm{N}$ increases (see also figure 9-a,e,f). Moreover, as shown by table 5, the anticorrelations between SSH and the Brunt-Väisälä frequencies (or MLD) are significantly higher than for Meddy 33, being both around -0.5.

The i-Ta and i-Sa (in figure 8-e,f) show an overall increasing trend throughout the Meddy 169 lifetime, though their growth-rate is halved when merger events stop feeding the initial Meddy (around April 2020). We attributed this behaviour to the fact that the Meddy 169 (whose structure is not significantly perturbed during its westward displacement), reaching the westernmost areas of the modeled region, encountered fresher and cooler waters. This was also confirmed by model-derived salinity and temperature climatologies at typical Meddy depths (not shown). Hence, even though the Meddy itself kept its overall structure almost unchanged, its thermohaline anomalies (at depth) became larger.

Like for the previous case, the overall characteristics of Meddy signatures can be summarized with tables 4 and 5. As for Meddy 33, the quantity which is best correlated with the evolution of the SSH anomaly is the integrated EPVa (with a value around 0.9). In 
the case of Meddy 169, the whole set of Meddy parameters (swirl velocities, radius and thickness) shows a significant correlation with the Meddy-induced SSH anomalies, with values exceeding 0.7 (the significance of the correlations is analogous to the one discussed in section 3.1.1). This behaviour is the expected one for isolated subsurface anticyclones, in idealized contexts [Bashmachnikov and Carton (2012), Ciani et al. (2015)]. Indeed, Ciani et al. (2015) showed that the SSH anomaly induced by isolated subsurface quasi-geostrophic anticyclones is proportional to $\Xi=\mathrm{i}$-EPVa $\cdot \mathrm{D}^{-2}$ (see also table 1 for a description of the variables). A further proof that Meddy 169 can be seen as an isolated feature is illustrated in figure 11. The scatter plot of the normalized time series of SSH anomaly (SSH anom*) and the quantity $\Xi^{*}$ is shown for both Meddy 33 and Meddy 169. The results of the scatter plot show that the proportionality between SSH anomalies and $\Xi$ is best verified for Meddy 169 , as also indicated by the linear fit of the data $\left(\mathrm{SSH}\right.$ anom $\left.{ }^{*}=1.12 \Xi^{*}-0.32\right)$. The existence of a negative intercept for the linear plot, though physically unacceptable, may be due to two facts: first, the theory dealt with uniformly stratified oceans, hence, did not account for geographical and/or seasonal variations of the Brunt-Väisälä frequency (which had an impact on the evolution of Meddy 169); moreover, the possibility of a threshold effect must be taken into account, indicating that a minimum i-EPVa content is required for a Meddy to have an observable surface signature (especially in presence of surface-turbulence). The possibility of a quadratic relation between $\Xi^{*}$ and SSH anom* is also excluded. Indeed, changing the linear fit for a quadratic fit does not improve the $\mathrm{R}^{2}$ value $\left(R^{2} \simeq 0.9 \mathrm{in}\right.$ both cases); therefore a linear relation between SSH anom* and $\Xi^{*}$ is satisfactory, and is supported by the regional model results. On the other hand, for Meddy 33, no linear relation can be established. Instead, the scatter plot evidenced the coexistence of two classes of values, schematically indicated as $\Omega_{1}$ and $\Omega_{2}$ in figure 11. The $\Omega_{1}$ group of values is related to the earlier stages of the Meddy 33 evolution, i.e., before it crossed the Azores front and experienced the bottom collision with a seamount. As previously stated, the high correlation between SSH anomaly and i-Ta and i-Sa for Meddy 169 is due to the combination of merger and the displacement of the Meddy towards fresher and cooler areas. The evolution of the Meddy surface thermohaline expressions is not correlated with the Meddy intrinsic/background oceanic properties (the $R_{P}$ coefficients never exceed 0.4 in both cases) as shown in section 3.1.1.

The maximum SSH anomaly induced by Meddy 169 is comparable with the one of Meddy 33. Indeed, the two eddies have comparable mean structures and their maximum surface expressions in SSH took place under similar background oceanic conditions (lower oceanic stratification above the eddy). Occurrences of positive and negative thermohaline anomalies at the surface are possible throughout the Meddy lifetime, hence, unlike SSH anomaly, they cannot uniquely be associated to the Meddy properties at depth [Oliveira 
et al. (2000), Bashmachnikov et al. (2013)].
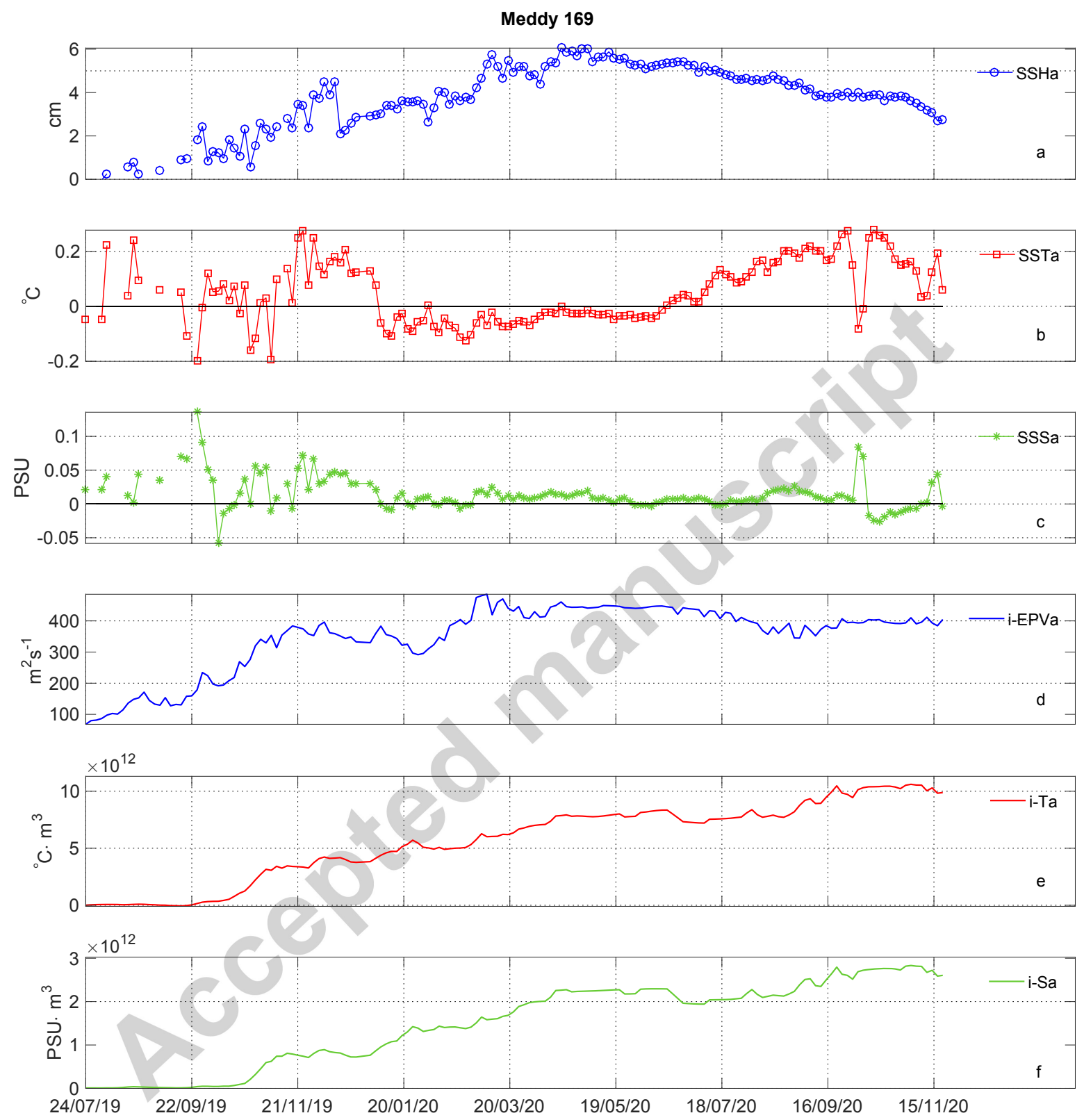

Figure 8: Surface signature and volume-integrated eddy parameters along the trajectory of Meddy 169 (see also Figure 3). a: SSHa (SSH anomaly, blue circles), b: SSTa (SST anomaly, red squares), $c$ : SSSa (SSS anomaly, green stars), d: i-EPVa (integrated Ertel potential vorticity anomaly, blue), e: i-Ta (integrated temperature anomaly, red), $f: i-S a$ (integrated salinity anomaly, green). 


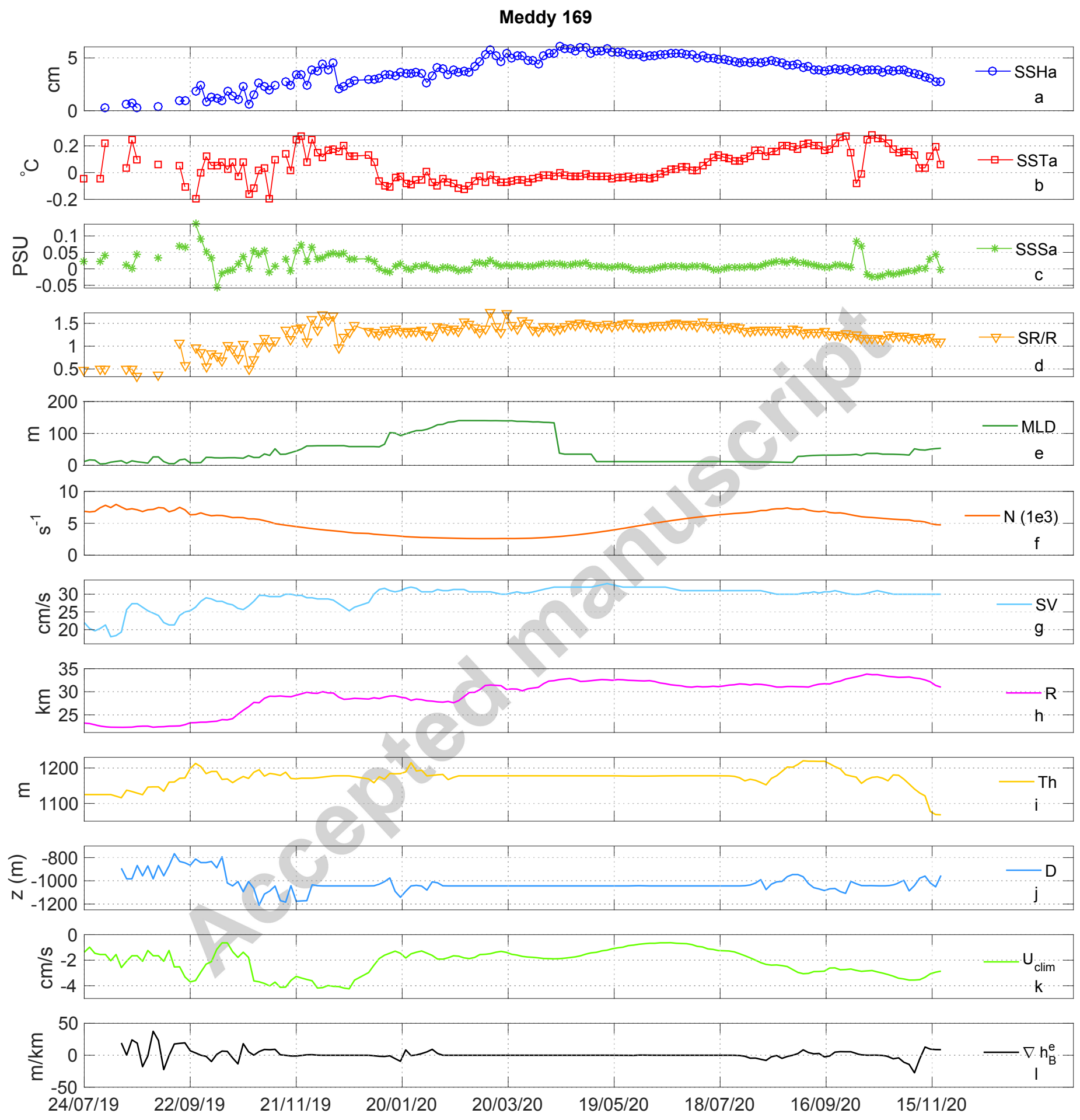

Figure 9: Surface signatures and Meddy/background properties along the trajectory of Meddy 169 (see also Figure 3). a: SSHa (SSH anomaly, blue circles), b: SSTa (SST anomaly, red squares), c: SSSa (SSS anomaly, green stars), $d: S R / R$ (Signature Radius over Meddy Radius, orange triangles), e: MLD (Mixed Layer Depth, green), $f: N$ (Brunt-Väisälä frequency, orange), g: SV (Meddy Swirl Velocity, cyan), h: R (Meddy Radius, magenta), $i$ : Th (Meddy thickness, yellow), $j$ : D4(Meddy Depth, light blue), $k$ : $U_{\text {clim }}$ (Intensity of climatological zonal surface currents, light green), $l: \nabla h_{B}^{e}$ (gradient of oceanic bottom topography, black). 

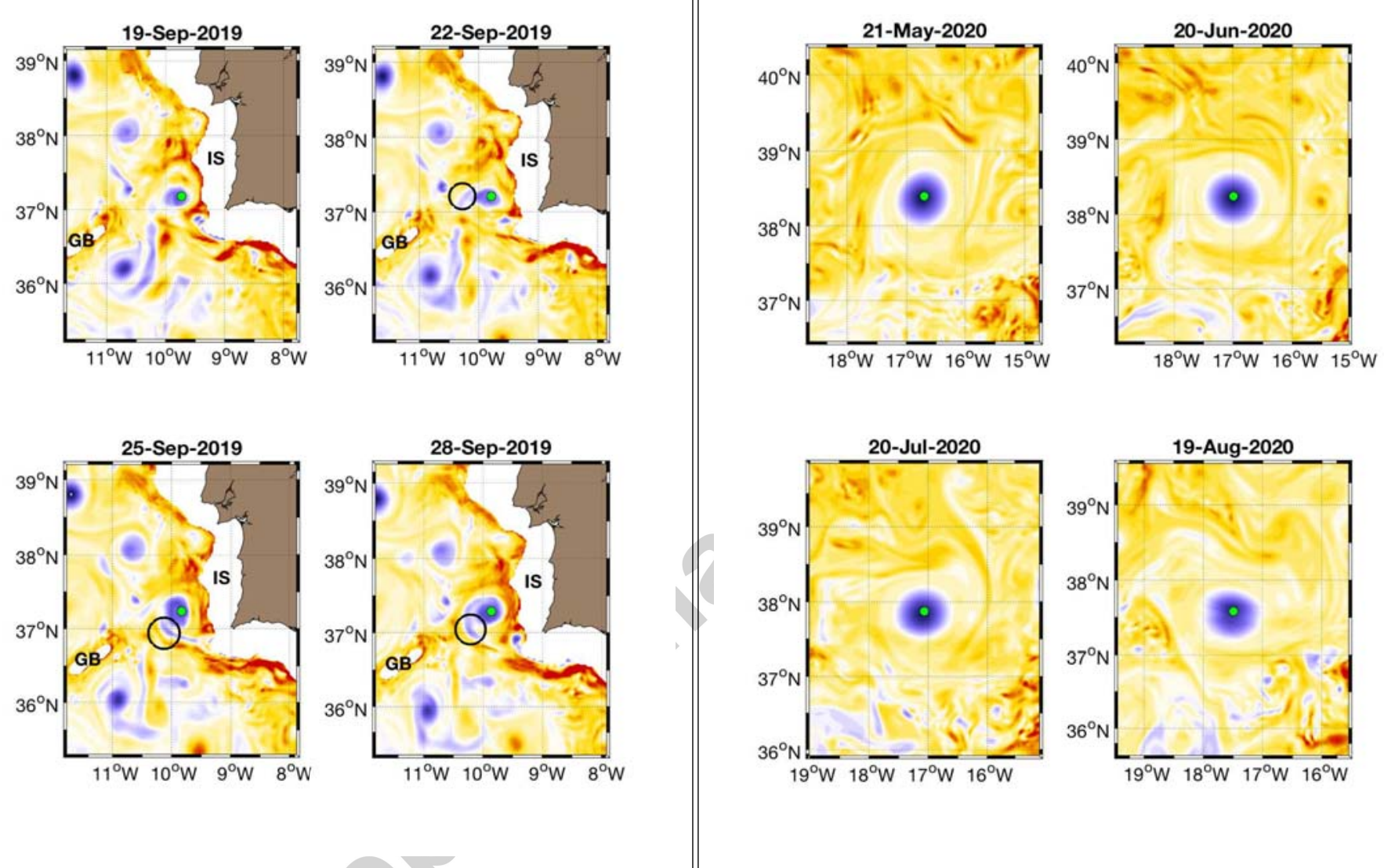

Figure 10: Left: merger of Meddy 169 with nearby small scale features (highlithted by the black circles) off Cape São Vicente. The white patch centered at $11.5^{\circ} \mathrm{W}$ and $36.5^{\circ} \mathrm{N}$ corresponds to the Gorringe Bank Seamount (GB); further east, the white patch is due to Iberian continental shelf (IS) (see also figure 3).). Right: instantaneous positions of Meddy 169 in May, June, July and August 2020 indicating the absence of merger events. Here the eddy can be considered as an isolated feature. In both panels, Meddy

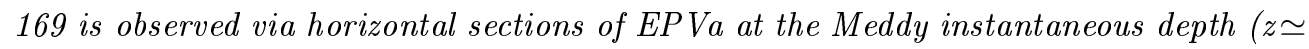
$-1000 \mathrm{~m}$ ). The green dot indicates the instantaneous position of the Meddy center (ETS output). 

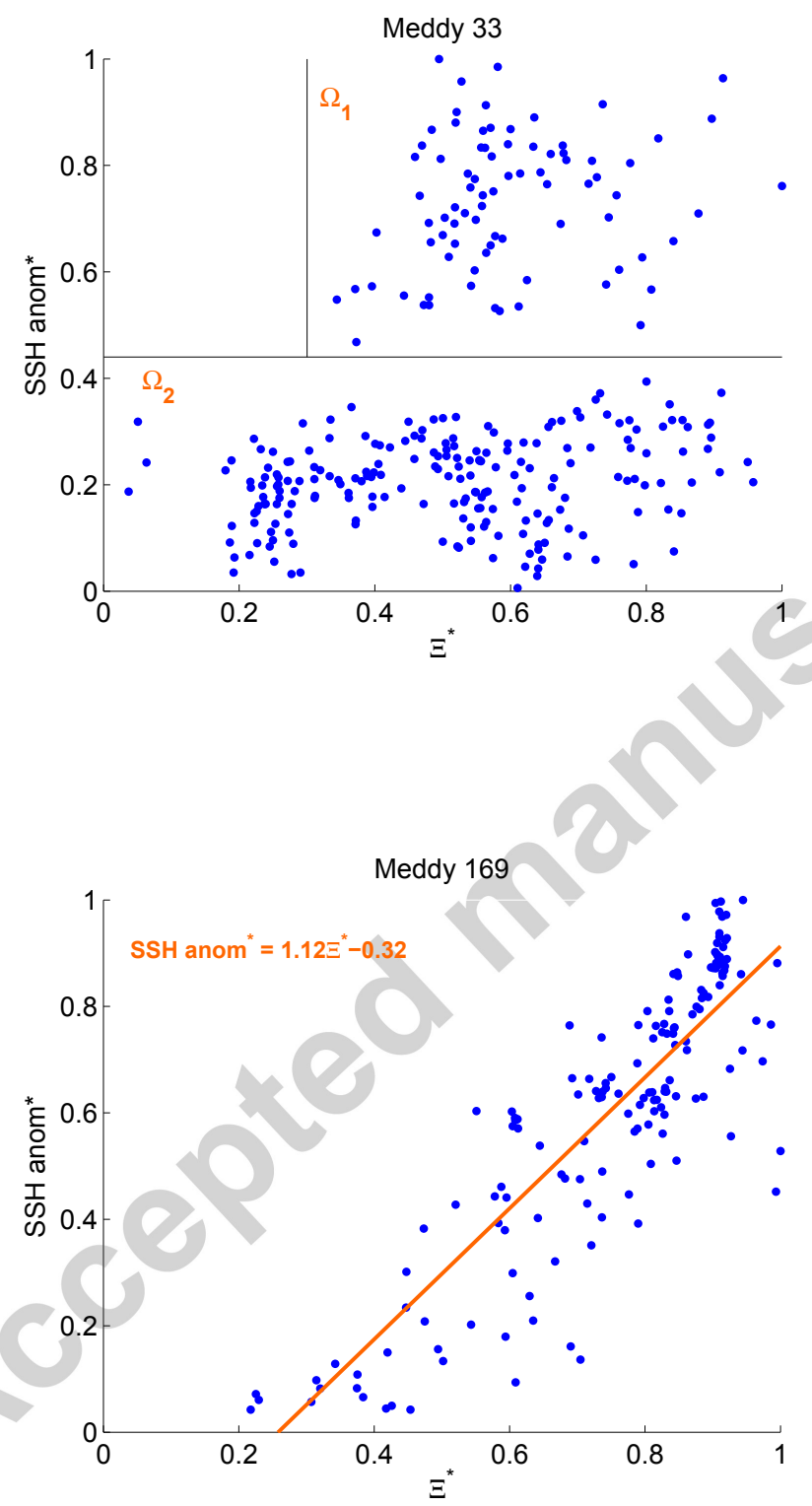

Figure 11: Scatter plot for the time series of SSH anomaly vs $\Xi=i$-EPVa. $D^{-2}$ (see table 1 for a description of the variables). The superscript " $*$ " indicates that normalized quantities have been used. Top panel: Meddy 33, Bottom panel: Meddy 169. The variables $\Omega_{1}$ and $\Omega_{2}$ are defined in the text. 
Table 4: Mean properties of Meddy 169 surface signatures.

\begin{tabular}{|c|c|c|c|}
\hline MEDDY 169 & $S S H_{\text {anom }}$ & $S S T_{\text {anom }}$ & $S S S_{\text {anom }}$ \\
\hline Max & $6.1 \mathrm{~cm}$ & $0.29^{\circ} \mathrm{C}$ & $0.13 \mathrm{PSU}$ \\
Min & $0.01 \mathrm{~cm}$ & $-0.21^{\circ} \mathrm{C}$ & $-0.06 \mathrm{PSU}$ \\
$\% \geq 0$ & 100 & 43 & 79 \\
$\%<0$ & 0 & 57 & 21 \\
\hline
\end{tabular}

Table 5: Pearson's correlation coefficients $\left(R_{P}\right)$ between the Meddy 169 surface-signatures and the along-trajectory Meddy/background ocean characteristics. The largest values are highlighted in red.

\begin{tabular}{|c|c|c|c|c|c|c|c|c|c|c|}
\hline MEDDY 169-R ${ }_{P}$ & M Swirl & M Radius & M Thick. & MLD & $\mathbf{N}$ & U clim & $\nabla h_{B}^{e}$ & i-EPVa & i-Ta & i-Sa \\
\hline $\mathrm{SSH}_{\text {anom }}$ & 0.78 & 0.82 & 0.72 & -0.47 & -0.52 & 0.23 & -0.27 & 0.91 & 0.6 & 0.6 \\
\hline MEDDY 169-R ${ }_{P}$ & M Swirl & M Radius & M Thick. & MLD & $\mathbf{N}$ & U clim & $\nabla h_{B}^{e}$ & i-EPVa & i-Ta & i-Sa \\
\hline $\mathrm{SST}_{\text {anom }}$ & -0.09 & 0.12 & 0.04 & 0.30 & 0.34 & -0.40 & -0.04 & -0.02 & 0.22 & 0.23 \\
\hline MEDDY 169-R ${ }_{P}$ & M Swirl & M Radius & M Thick. & MLD & $\mathbf{N}$ & U clim & $\nabla h_{B}^{e}$ & i-EPVa & $\mathbf{i}-\mathbf{T a}$ & i-Sa \\
\hline $\mathrm{SSS}_{\text {anom }}$ & -0.31 & -0.30 & -0.35 & 0.15 & 0.20 & -0.27 & 0.23 & -0.28 & -0.42 & -0.39 \\
\hline
\end{tabular}

\subsubsection{The case of a "south-southwestward moving Meddy": Meddy 120}

We conclude the comparative study of the longest-lived Meddies in the model by analyzing the case of Meddy 120. Like Meddy 169, it originated near Cape São Vicente, its initial coordinates being $37^{\circ} \mathrm{N}$ and $9^{\circ} \mathrm{W}$ (see also figure 3 ). This eddy, whose lifetime is around 1.7 years, is mostly characterized by a south-southwestward drift (see e.g. figure 3). A looping trajectory is observed between November 2013 and late October 2014 (more precisely in the time-window bounded by the cyan diamonds and triangles in figures 3, 13-a and 14-a). Visual inspection of the Meddy evolution at $1000 \mathrm{~m}$ depth, evidenced the two main causes of this behaviour, namely, a series of Meddy/eddy and Meddy/topography interactions. In particular, Meddy 120 interacted with several cyclonic features that repeatedly modified its direction of movement. Indeed, between November 2013 and October 2014, Meddy 120 occupied a region where subsurface cyclones were abundant [Serra et al. (2010)]. Some of these subsurface cyclones were generated by the stirring of positive EPVa from the Moroccan continental shelf and nearby seamounts, due to the action of other Meddies ( in a similar fashion as described in Vic et al. (2015)) (see e.g. the 21-Dec-2013 panel of figure 12: a Meddy located at $34.5^{\circ} \mathrm{N}-9^{\circ} \mathrm{W}$ stirs a positive EPVa patch eventually evolving in an anticyclonic feature, highlighted by the black circles). As a result, Meddy 120 underwent a series of couplings with subsurface cyclones, that, via dipolar and tripolar effects, spatially 
bounded the Meddy forcing it to loop (figure 12 shows a case of dipolar drift). Another point that makes Meddy 120 a particular case study is that it spent $70 \%$ of its lifetime in a highly turbulent region, where eddy activity is also very intense at the sea-surface. Indeed, the Meddy initially drifted and looped close to the area where the imprint of the Azores front is more intense (see e.g. figures 1 and 3), hence, where surface-intensified cyclones and anticyclones are abundantly ejected by the meandering of the Azores front [Barbosa Aguiar et al. (2011)]. This had consequences on the surface expression of the Meddy, which exhibited an oscillatory signal seldom correlated with the behaviour of the i-EPVa, if compared to Meddy 33 and 169 (see e.g. figure 13-a,d). Indeed, despite the initial evolution of the i-EPVa and the visual inspection of EPVa maps at the depth of Meddy 120, indicating the occurrence of a merger (not shown), the SSH anomaly was affected by the repeated interaction with surface cyclones and anticyclones.

It is also worth noticing that, in this case, the Meddy surface expression is very intermittent, if compared to the previous cases (only $67 \%$ of its surface signature time evolution could be described). Indeed, the Meddy surface signature detection algorithm, described in section 2, automatically discards all cases in which the surface OW fields do not comply with the structure shown in figure 2 (i.e. an OW minimum within 1.5 Meddy radii distance from the surface projection of the Meddy center). In other words, the highly intermittent surface-signature is a further (although indirect) proof of the turbulent surface activity above Meddy 120. As expected, the scatter plot of the normalized time series of SSH anomaly and the quantity $\Xi=\mathrm{i}-\mathrm{EPVa} \cdot \mathrm{D}^{-2}$ suggests that no significant linear relation exists between these two quantities (not shown). In this case, because of the coupling with the subsurface cyclones, the turbulence at the sea-surface and the interactions with topographical features, the theoretical law based on the approximation of "isolated Meddy" [Bashmachnikov and Carton (2012), Ciani et al. (2015)] could not be verified.

When the Meddy stopped looping and eventually drifted south of the turbulent region (in October 2014), its surface-signature clearly reappeared at the sea-surface. The corresponding SSH anomaly (from late October 2014 onward) exhibited values never exceeding $2 \mathrm{~cm}$ until the end of the Meddy lifetime, i.e., when it reached the model sponge layer (see figures and 3 and 14-a). Such low values are explained by the degradation of Meddy 120, evidenced by the decreasing trend in the i-EPVa, i-Ta and i-Sa (shown in figure 13-d,e,f), as well as by the decreasing swirl velocity (see figure 14-g). Also, in the last months of the Meddy lifetime, its almost straightforward-southward trajectory is consistent with the results of Colin de Verdière (1992). Indeed, the Meddy 120 exhibited an increasing radius (until mid-March 2015; with a trend, computed between October 2014 and mid-March 2015, of around $300 \mathrm{~m} / \mathrm{month}$ ) and a decreasing thickness (with a trend of $-20 \mathrm{~m} / \mathrm{month}$, evaluated from October 2014 onward) (figure 14-h,i). 

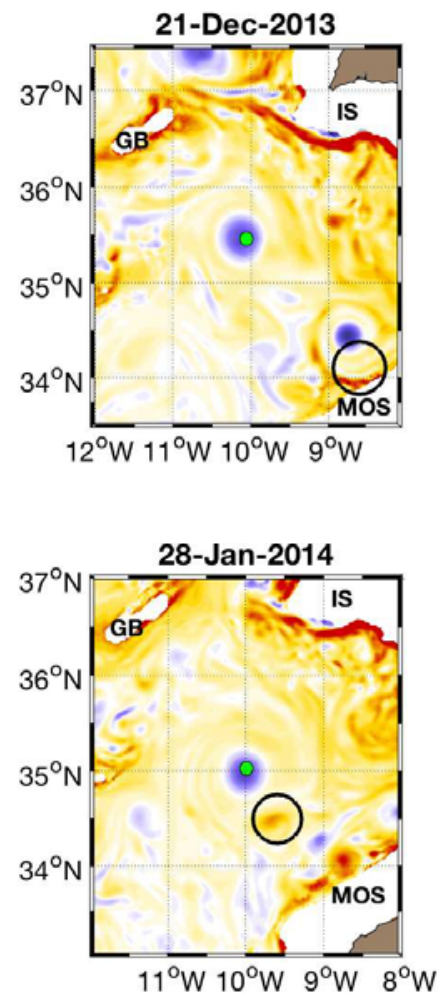
lifetime.

(1)
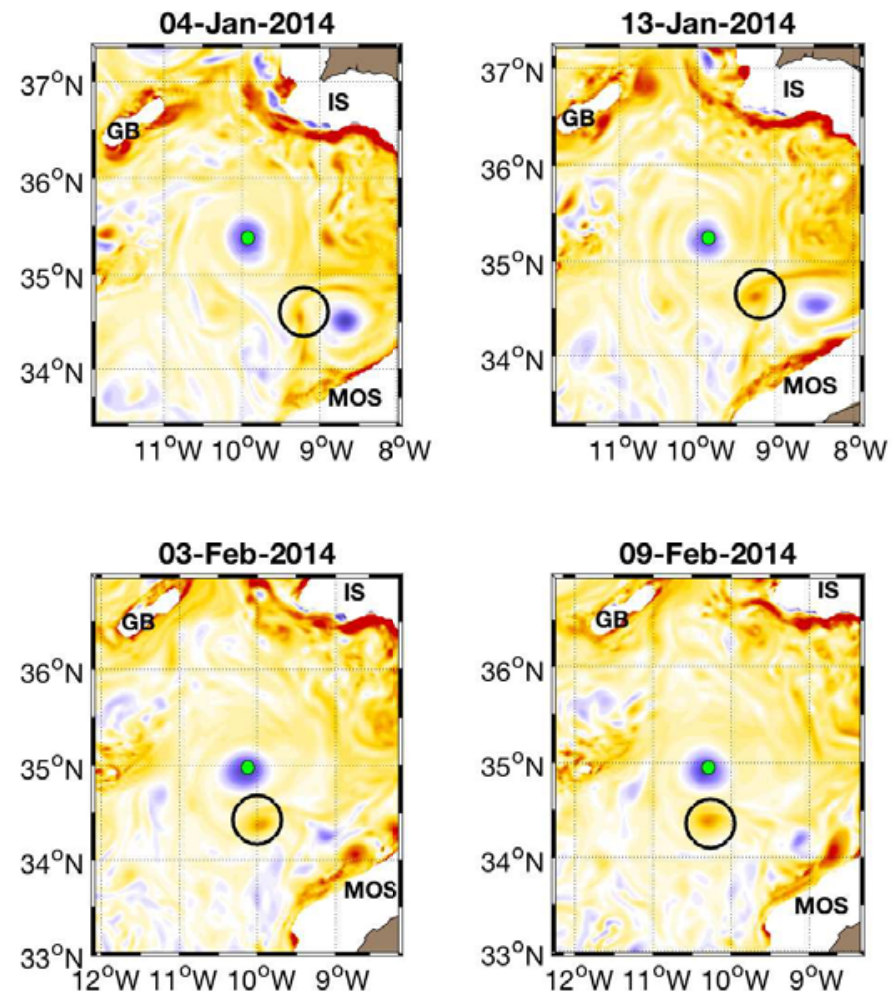

Regarding the Meddy-induced surface salinity and temperature anomalies, their evolution is completely analogous to the case of Meddies 33 and 169. Furthermore, we do not show the table containing the Pearson's correlation coefficients because, as one could expect from observation of figures 13 and 14, none of the coefficients exceeds 0.4 , indicating that correlations are not significant. Once again, we attribute this to the highly turbulent region (both at depth and in proximity of the sea-surface) in which Meddy 120 spent most of its
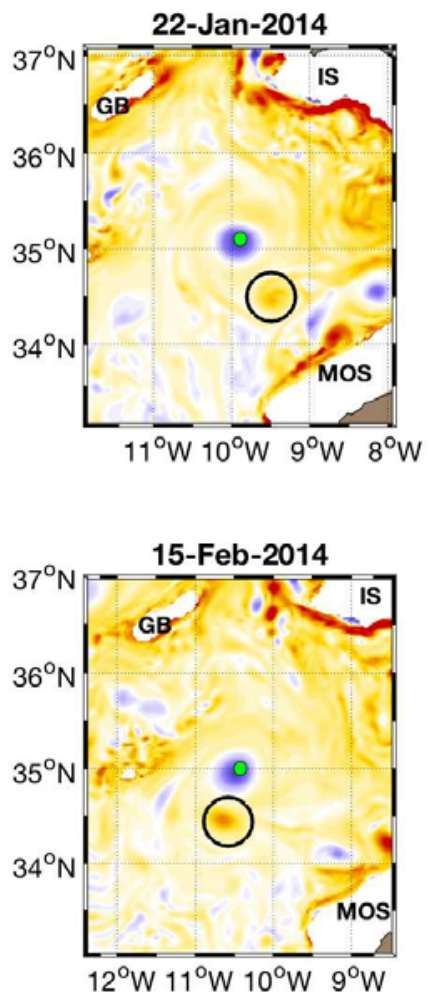

Figure 12: Coupling of Meddy 120 with a subsurface cyclone. The cyclone is generated by the stirring of positive EPVa along the Moroccan continental shelf due to another Meddy (see e.g the Meddy located at 34. $5^{\circ} \mathrm{N}-9^{\circ} \mathrm{W}$ on 21-Dec-2013; the evolution of the positive EPVa patch is highlighted by the black circles). The Meddy 120 evolution is shown by horizontal sections of EPVa at the Meddy depth $(z \simeq 1000 \mathrm{~m})$. The instantaneous position of Meddy 120 is given by the green dot (ETS output). The Gorringe Bank Seamount, the Moroccan and Iberian continental shelves are respectively labeled as GB, MOS and IS (see also figure 3). 

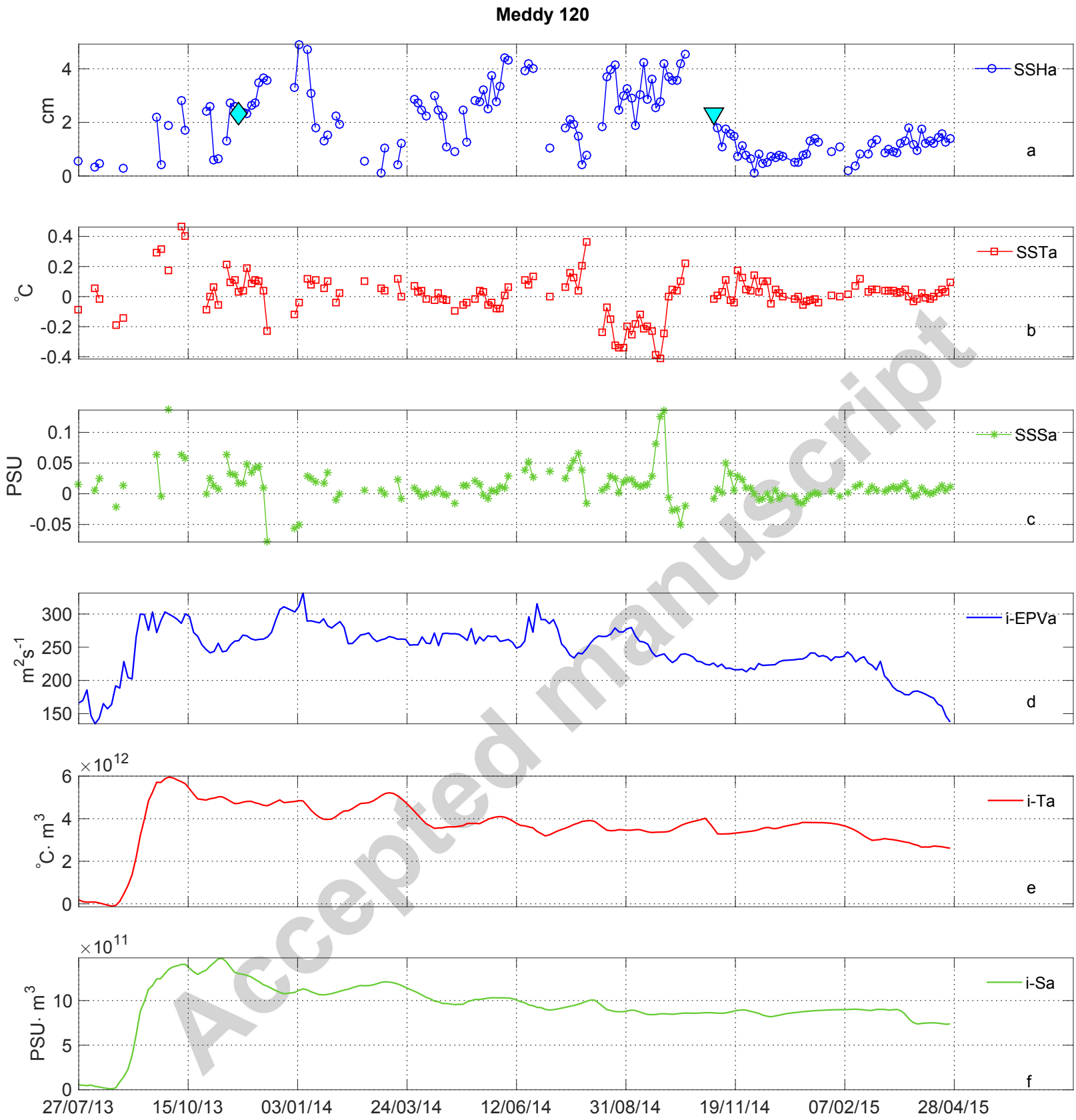

Figure 13: Surface signature and volume-integrated eddy parameters along the trajectory of Meddy 120 (see also Figure 3). a: SSHa (SSH anomaly, blue circles; the cyan diamond and triangle are commented in section 3.1.3), b: SSTa (SST anomaly, red squares), $c$ : SSSa (SSS anomaly, green stars), d: i-EPVa (integrated Ertel potential vorticity anomaly, blue), e: i-Ta (integrated temperature anomaly, red), $f: i$-Sa (integrated salinity anomaly, green). 


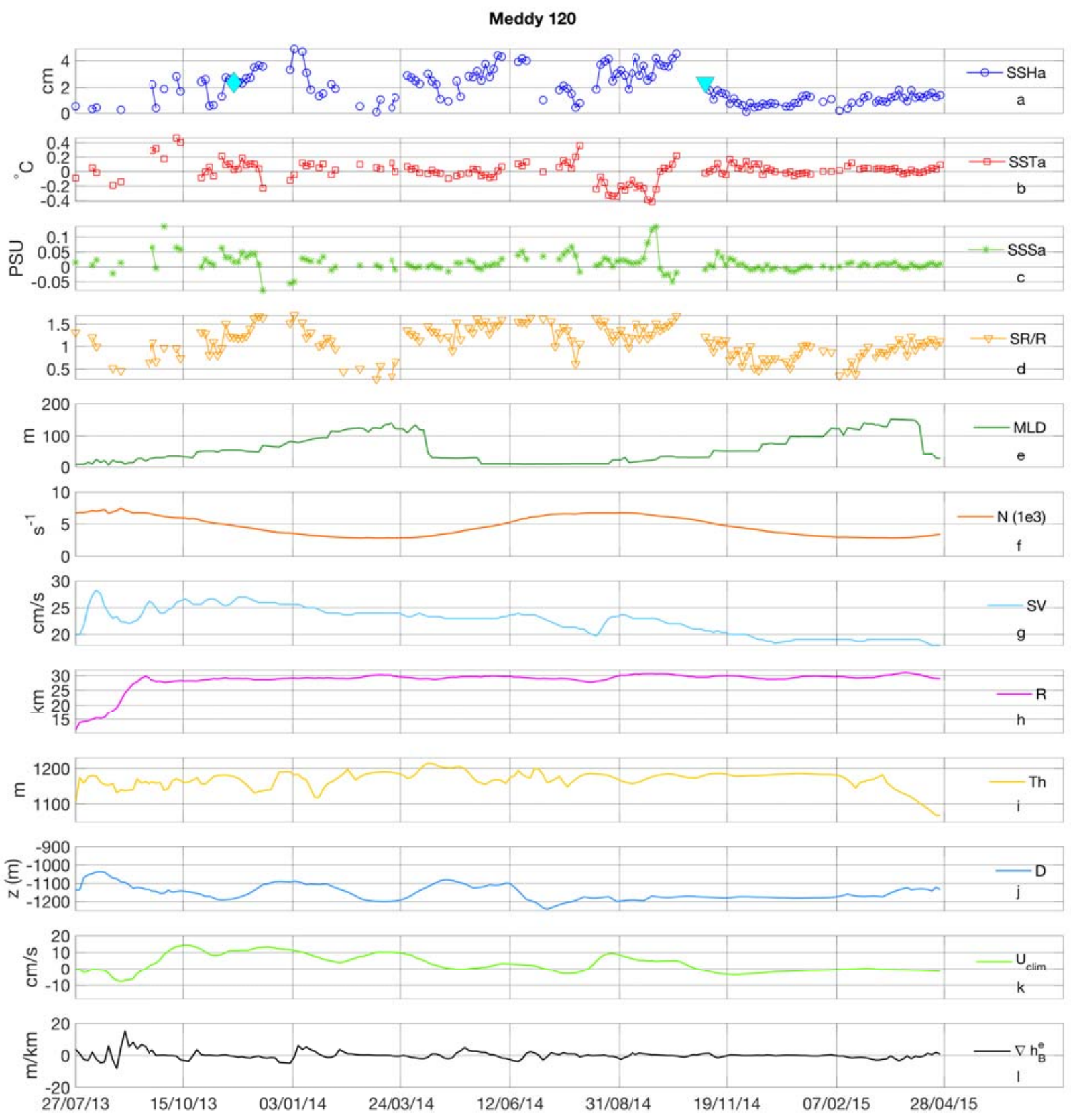

Figure 14: Surface signatures and Meddy/background properties along the trajectory of Meddy 120 (see also Figure 3). a: SSHa (SSH anomaly, blue circles; the cyan diamond and triangle are commented in section 3.1.3), b: SSTa (SST anomaly, red squares), c: SSSa (SSS anomaly, green stars), d: SR/R (Signature Radius over Meddy Radius, orange triangles), e: $M L D$ (Mixed Layer Depth, green), $f: N$ (Brunt-Väisälä frequency, orange), g: SV (Meddy Swirl Velßdity, cyan), $h: R$ (Meddy Radius, magenta), $i$ : Th (Meddy thickness, yellow), j: D (Meddy Depth, light blue), $k: U_{\text {clim }}$ (Intensity of climatological zonal surface currents, light green), $l: \nabla h_{B}^{e}$ (gradient of oceanic bottom topography, black). 


\subsection{Statistics of SSH anomalies over modeled Meddies}

In sections 3.1.1, 3.1.2 and 3.1.3 we showed that, among the Meddy-induced sea-surface signatures, the SSH anomalies are the ones exhibiting the most significant correlations with the Meddy and the background oceanic parameters (unless Meddies spend most of their lifetime in highly turbulent regions). These results motivated us to investigate a larger set of Meddies, i.e., all the Meddies of Group 1 (lifetime $>2$ years) and Group 2 (2 years > lifetime $>1$ year) that could be successfully detected in the OW fields for at least $80 \%$ of their lifetime (see also sections 2 and 3 for further details). In this case, since we dealt with a large number of Meddies (total number $=86$ ), we provide an overall description of the SSH anomaly evolution. In particular, we show which of the correlations between the Meddy surface signature (in SSH fields) and the Meddy/background oceanic parameters are the most significant. The Meddies were divided in two main groups, according to the pathway of their trajectories, regardless of their duration. The two groups are schematically represented in figure 15-a, where blue and red trajectories refer to westward moving Meddies and southwestward moving Meddies. These groups respectively indicate Meddies whose trajectories entirely lie north of the climatological imprint of the Azores front (27 Meddies) and Meddies that could cross it, eventually reaching the southernmost areas of the region of study (59 Meddies). Considering the size of our dataset, we assume our sample to be statistically significant and that no other simulations are needed to confirm the results we are about to present.

Table 6: Averaged Pearson's correlation coefficients $\left(R_{P}\right)$ between the Meddies swirl velocity (SV, in $\mathrm{cm} / \mathrm{s})$, integrated Ertel potential vorticity anomaly $\left(i-E P V a, \mathrm{~m}^{2} / \mathrm{s}\right)$ and the Meddiesinduced SSH anomalies. The coefficients are shown for the westward moving and the southwestward moving Meddies.

\begin{tabular}{c|cc} 
Westward Moving $(\mathbf{n}=\mathbf{2 7})$ & & \\
\hline Meddy Parameter & SV & i-EPVa \\
\hline $\mathrm{R}_{P}$ (SSH anomaly) & 0.45 & 0.50 \\
\hline & & \\
\hline Southwestward Moving $(\mathbf{n}=\mathbf{5 9})$ & & \\
\hline Meddy Parameter & SV & i-EPVa \\
\hline $\mathrm{R}_{P}$ (SSH anomaly) & 0.42 & 0.45 \\
\hline
\end{tabular}

Table 6 shows ther average Pearson's correlation coefficients between the Meddies SSH anomalies and their swirl velocity (SV) and integrated potential vorticity anomaly (i-EPVa). For the westward moving Meddies such values are respectively 0.45 and 0.50 , while, for the southwestward moving ones, they are 0.42 and 0.45 (lower compared to the cases of Meddy 

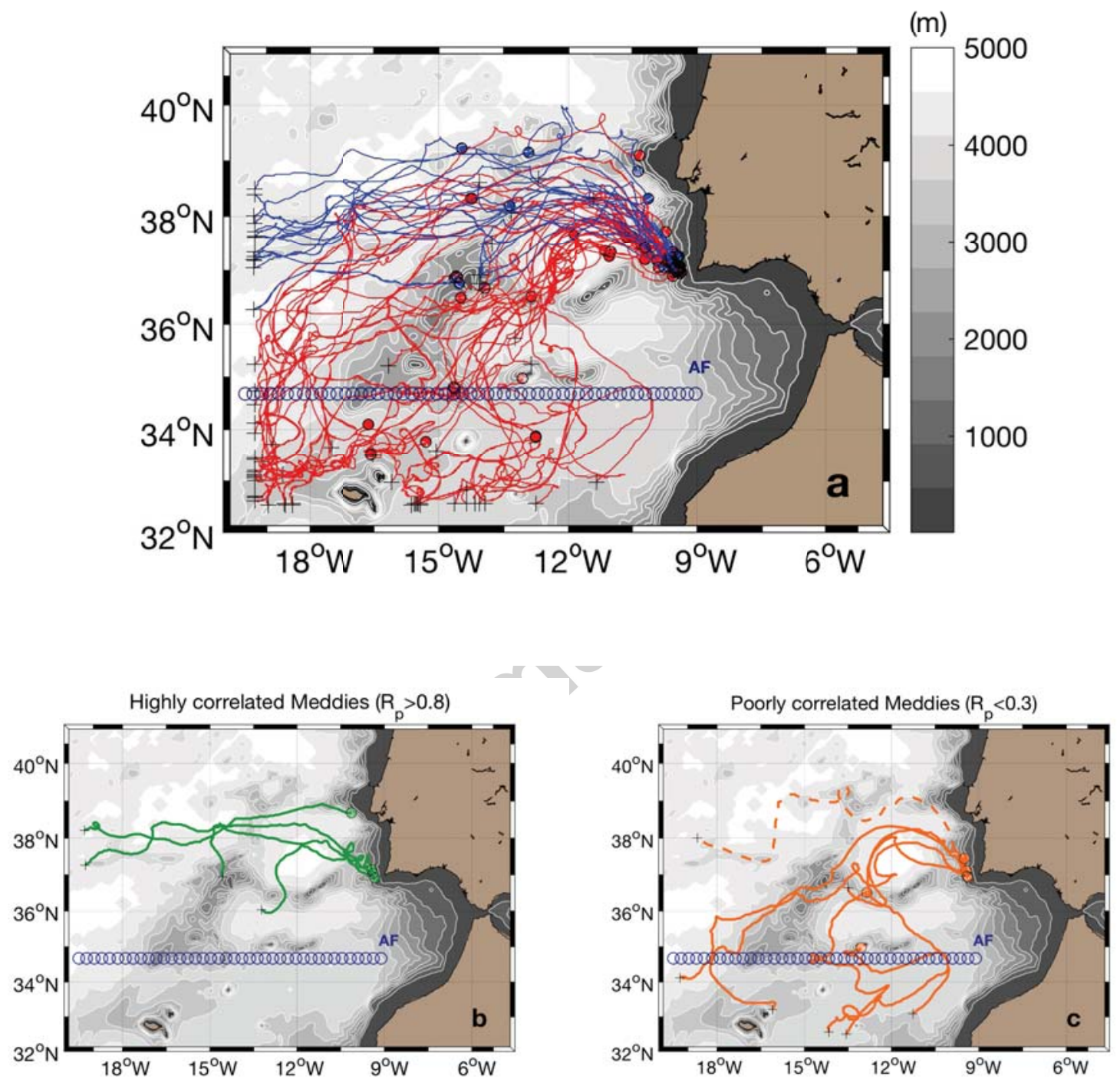

Figure 15: a) Trajectories of Meddies belonging to Group 1 and 2 (see also section 3 for further details) over bathymetry. Blue and red trajectories are for westward moving Meddies and southwestward moving Meddies, respectively; b) highly correlated Meddies ( $R_{P}$ between the SSH anomalies and the $i-E P V a / S w i r l$ Velocity higher than 0.8), green trajectories; c) poorly correlated Meddies ( $R_{P}$ between the SSH anomalies and the $i$ $E P V a / S w i r l$ Velocity lower than 0.3), orange trajectories. The blue circles indicate the mean axis of the Azores front (AF) in the model. 
33 and 169). Also, this result is almost unchanged if we focus on the Meddies living more than 2 years in the simulation. This indicates that, by selecting Meddies of Group 1 and 2 (lifetimes larger than 1 year) one can satisfactorily describe the overall behaviour of the longest-lived Meddies in this simulation.

A closer look at this subset of Meddies evidenced that the ones exhibiting the highest correlations $\left(\mathrm{R}_{P}>0.8\right)$ between the induced SSH anomalies and the i-EPVa (or swirl velocity) share the following properties:

- their trajectory is mostly rectilinear or it evolves far from the most prominent topographic features in the region for more than $75 \%$ of its total length (suggesting a marginal interaction with seamounts);

- their in-depth structure, as well as their dynamical imprint at the sea-surface, can be considered as isolated. This means that these Meddies, except for the merger events with smaller Meddies at depth, evolved far from same-size Meddies and did not undergo any subduction with fronts or vertical alignment with surface-intensified eddies. Indeed, none of them crossed (or approached) the climatological axis of the Azores front (AF in figure 15), where the generation of meanders and the ejection of eddies is frequent.

Such Meddies are schematically indicated in figure 15-b as the "highly correlated Meddies". On the other hand, the "poorly correlated Meddies" (see figure 15-c), exhibit the lowest correlations $\left(\mathrm{R}_{P}<0.3\right)$ between the induced SSH anomalies and the i-EPVa (or swirl velocity). The visual inspection of their evolution evidenced the following reasons for this behaviour:

- all of the Meddies (except for Meddy 174, highlighted by the dashed trajectory in figure 15-c) interacted with the most prominent seamounts in the region of study and their trajectories crossed the climatological axis of the Azores front. Thus, none of them could be considered as isolated and underwent a series of collisions with seamounts and of interactions with surface-intensified dynamical features (i.e. eddies, meanders and fronts);

- the particular case of Meddy 174 (dashed trajectory in figure 15-c) proved that the low correlations between a Meddy i-EPVa (or swirl velocity) and its induced SSH anomalies can be due to the proximity of other same-size or larger Meddies without merger occurrence. Indeed, the Meddy 174 lived for 13 months and it spent around 7 months swirling near other Meddies. The simultaneous evolution of the EPVa (evaluated at depth) and of SSH fields proved that its surface signature interacted with the one of the nearby Meddy. This mechanism ended up generating a single SSH 
anomaly which was mostly driven by the second Meddy, unmatching the dynamical surface response due to the presence of the Meddy 174 alone (e.g. the one predicted by the theory of isolated vortices [Bashmachnikov and Carton (2012), Ciani et al. (2015)]), (not shown).

The highly and the poorly correlated Meddies respectively represent the ideal and worse cases in which one can characterize the long-term behaviour of a Meddy surface signature and relate it to its internal integrated EPV anomaly ${ }^{2}$. In the middle, there can be a combination of these two configurations leading to the average correlations that we obtained for the set of the longest-lived Meddies, shown in table 6. Furthermore, after this closer look at the subset of the longest-lived Meddies, it is not surprising to obtain slightly larger mean correlations for the group of the westward moving Meddies, compared to the southwestward moving ones. Indeed, the westward moving Meddies drift more rapidly towards the open ocean, hence, they have minor chances (though not zero) to:

- collide with seamounts;

- interact with nearby Meddies (that are mostly confined within the first $600 \mathrm{~km}$ from the Iberian coasts, see also Bashmachnikov et al. (2015));

- interact with surface-intensified eddies and meanders, being far from the climatological axis of the Azores front.

In general, table 6 indicates that the dominating factors in driving the surface expression of Meddies in SSH fields are the Meddy integrated potential vorticity anomaly and its rotation rate (notice that this latest variable is actually contained in the Meddy potential vorticity via the relative vorticity, [Vallis (2006)]). All the other correlations are not shown as they never exceed the value of \pm 0.2 (except for the Meddy radius for the westward moving Meddies, where $\mathrm{R}_{P}=0.33$ ). Hence, excluding specific cases, like the one of Meddy 120 (see section 3.1.3), we can state that, once again, the Meddy i-EPVa proves to be the key factor in determining the surface expression of Meddies in terms of SSH anomaly all along the Meddy trajectory.

\section{Discussion and Conclusions}

In this paper, we have investigated the surface expression of Mediterranean water eddies (Meddies) in a realistic numerical simulation (using the model ROMS [Shchepetkin

\footnotetext{
${ }^{2}$ The scatter plots between the SSH anom* and $\Xi^{*}=\left(\mathrm{i}-\mathrm{EPVa} \cdot \mathrm{D}^{-2}\right)^{*}$, as done for Meddy 33 and 169 (see e.g. figure 11), yield linear distributions for the highly correlated Meddies only, further confirming that they evolve in more idealized conditions compared to the poorly correlated ones
} 
and McWilliams (2005)]). For this purpose, we took advantage of a model initially built to determine a census of Meddies characteristics (mainly generation sites, radii, vertical extents, propagation patterns and rotation rates) via a numerical approach. These results are thoroughly described in Barbosa Aguiar et al. (2013) and showed a very good agreement with previous studies based on hydrological surveys [Bower et al. (1997), Richardson et al. (2000a), among others]. Our aim was to provide a first long-term description of the surface signatures generated by Meddies, generally found at depths around $1000 \mathrm{~m}$, to help evaluating the possibility of a future tracking via observations the sea-surface, including a synergy between SSH/SST/SSS observations. The work consisted in studying the surface signature of a large number of Meddies (around 90) in the model. The novelty, as well as the main advantage of this approach was the simultaneous availability of the three-dimensional Meddy structure, the oceanic background conditions and sea-surface height, temperature and salinity.

Firstly, we studied the evolution of the longest-lived Meddies in the model, selecting three Meddies exhibiting different types of trajectories: purely westward, southwestward and southward. All of these Meddies had mean radii, swirl velocities and depths around 30 $\mathrm{km}, 20 \mathrm{~cm} / \mathrm{s}$ and $1000 \mathrm{~m}$, respectively.

In the first two cases (i.e. Meddy 33 and 169), the integrated potential vorticity anomaly (i-EPVa) proved to be the main factor in driving the Meddy surface signature in terms of SSH anomaly (with Pearson's correlation coefficients between i-EPVa and SSH anomalies around 0.7 and 0.9 for Meddy 33 and 169, respectively). The Meddies always exhibited positive SSH anomalies and the maximum values were around $7 \mathrm{~cm}$ (around $30 \%$ of the largest SSH anomalies associated with the mesoscale surface structures in the region of study [Barbosa Aguiar et al. (2011)]); the corresponding maximum horizontal extent of the surface-signature was around 1.5 Meddy radii and this is in the range of values predicted in Bashmachnikov et al. (2014). Bashmachnikov and Carton (2012) reviewed the characteristics of several real oceanic Meddies detected via in-situ observations (see their table 1). They showed that Meddies with structures comparable to the ones analyzed in this study, can generate sea-level anomalies within the 5 to $13 \mathrm{~cm}$, which is in agreement with the maximum SSH anomalies observed for Meddy 33 and 169.

On the other hand, as also stated by Oliveira et al. (2000), the Meddy thermohaline surface signatures exhibited positive and negative values all along the Meddy trajectory and never showed significant correlations with the Meddy integrated salt and heat content. Such behaviour confirmed that the oceanic surface conditions prevail on the Meddy-induced thermohaline surface expression.

In the third case, the Meddy (Meddy 120) spent most of its lifetime in a highly turbulent region, i.e., where surface and subsurface eddies are abundant. At the sea-surface, such 
eddies are mostly generated by the instability of the Azores front, while the MO and the stirring of vorticity in meddy/topography interactions (like described in Vic et al. (2015)) mostly produce vortical structures at typical Meddy depths. The combined action of the surface and subsurface eddies gave Meddy 120 an unusual looping trajectory and an intermittent surface expression. Indeed, while the Meddy was looping at depth, its surface expression interacted with the surface eddies ejected by the Azores front (see e.g Barbosa Aguiar et al. (2011)). As a result, Meddy 120 exhibited a very noisy surface expression, often undetectable in the surface OW fields.

Excluding cases like the one of Meddy 120, the link between the Meddy i-EPVa and its surface expression in SSH fields is also verified for all the Meddies that lived more than one year in the simulation.

Significant changes in the evolution of Meddies surface signature in SSH fields are mainly caused by the following factors (mostly given to changes in the Meddy i-EPVa structure):

- vertical alignment of the Meddy with surface anticyclones and interaction with cyclonic features, respectively resulting in an increase and a decrease of the intensity in the SSH anomaly;

- merger of a Meddy with surrounding Meddies, mostly in the first $600 \mathrm{~km}$ from the Iberian coast (see also Bashmachnikov et al. (2015)), causing an increase in the SSH intensity;

- lateral/bottom collision of a Meddy with seamounts, both causing a degradation of the Meddy SSH anomaly. For the case of Meddy 33, we also showed that bottom collisions with seamounts can be more destructive than the lateral ones;

In particular, the role of merger proved to be crucial for the detectability of Meddies in SSH fields. Newly formed Meddies, though younger and less eroded by the interaction with bottom topography or by lateral and vertical diffusion [Armi et al. (1989), Shapiro et al. (1995)] are often too small in size and their potential vorticity content is weak for their surface signature to exceed the threshold of $1 \mathrm{~cm}$ (which is also the threshold required by most eddy tracking methods based on SSH observations, see e.g. Qiu-Yang et al. (2016)). Merger feeds the original Meddy structure with potential vorticity and progressively allows the Meddy to develop its surface signature. Indeed, the highest increases in Meddy-induced SSH anomalies were always registered after a series of coalescence events; the increase was around $600 \%$ for the case of Meddy 169 .

This work also indicates that a synergy between SSH, SST and SSS fields, that proved to be useful to study surface and near-surface-intensified motions (see e.g. Lapeyre and Klein (2006) and Isern-Fontanet et al. (2008)), is not helpful to track Meddies along their 
whole trajectories. Instead, the SSH anomalies proved to be the most reliable signature of an underlying Meddy. Lapeyre and Klein (2006) and Isern-Fontanet et al. (2008) pointed out that, given the horizontal distribution of the meridional large scale oceanic potential vorticity, the oceanic subsurface dynamics can be reconstructed from sea-surface density (SSD hereinafter) and temperature, respectively. Indeed, in the framework of the surface quasi-geostrophic theory, the SSD can be seen as a source of potential vorticity for the ocean interior. In that context, it was shown that the reconstruction was only possible in the first $500 \mathrm{~m}$ of the water column. Hence, it is not surprising to ascertain that, in our study, surface patterns of temperature (and salinity) are not correlated with the Meddy motions, i.e., at depths that can even exceed $1000 \mathrm{~m}$.

More recently Ponte and Klein (2013), taking advantage of an idealized numerical simulation based on the ROMS model, tried to reconstruct the oceanic subsurface dynamics from the modeled SSH field. This approach, relying on SSH fields only, makes the reconstruction possible even when SSD anomalies are weak, confirming that a relation between SSH and internal potential vorticity anomalies can be established (even though the nearsurface layers are generally better reconstructed than the intrathermocline ones). In our study, despite the depth of the Meddies $(1000 \mathrm{~m})$, the Meddy-induced SSH anomalies could be detected and they were supported by the Meddy potential vorticity structure at depth (iEPVa). Even when abrupt changes in the Meddy structure took place, the Meddy-induced SSH anomalies could still exhibit intensities not far from $2 \mathrm{~cm}$, which is compatible with present day along-track altimetric observations and the future 2D SWOT measurements threshold. Moreover, this study suggests that the SWOT mission can help improving the Meddies detection in the early stages of their lifetime, when their SSH anomalies have horizontal extents around 10-20 km (which could not be captured by the present-day gridded altimetric data [Dibarboure et al. (2011)]).

The knowledge of the Meddies mean pathways and generation sites as well as the use of hydrological data (e.g. ARGO floats) remain ancillary to identify an initial position for the Meddy. Then, an automatic tracking could be achievable via satellite altimetry. Indeed, a natural follow-up of this study could consist in applying the SWOT sampling simulator [Gaultier et al. (2017)] to the outputs of the simulation described in Barbosa Aguiar et al. (2013). This could help quantifying the capability of SWOT measurements for the tracking of the Meddies signatures in SSH fields. We also believe that the use of realistic models (like the one described in Barbosa Aguiar et al. (2013)) in combination with satellite sampling simulators could improve the study of all those "weak" eddy signatures which are nowadays considered as noise and discarded (e.g. all the ones below the $1 \mathrm{~cm}$ threshold [Qiu-Yang et al. (2016)]). Indeed, working with models allows one to distinguish the weak signatures due to the construction of the altimetric products from the ones associated to robust eddies 
(like e.g. the SSH anomalies of newly formed or decaying Meddies).

Moreover, the present model study could benefit from the use of a higher frequency atmospheric forcing, which could improve the characterization of the Meddies thermohaline surface signatures. Indeed, the simulation analyzed here is forced by monthly climatological fields, which can give smoother evolutions of SST and SSS, if compared to real remotelysensed data.

\section{Acknowledgements}

The authors wish to thank the Université de Bretagne Occidentale (UBO), the Région Bretagne and the LabexMER for funding this study. The support of Consiglio Nazionale delle Ricerche (CNR) via the "Progetto Bandiera RITMARE" and Collecte Localisation Satellites (CLS) is also acknowledged. D. Ciani also wishes to thank the four anonymous Reviewers for their clever remarks about this paper, Ettore Salusti for the fruitful discussions about this work during the EGU2017 General Assembly and Marie-Hélène Rio, who kindly supported the finalization of this paper. 
Armi, L., Hebert, D., Oakey, N., Price, J. F., Richardson, P. L., Rossby, H. T., Ruddick, B., 1989. Two years in the life of a mediterranean salt lens. Journal of Physical Oceanography 19 (3), 354-370.

Armi, L., Zenk, W., 1984. Large lenses of highly saline Mediterranean water. Journal of Physical Oceanography 14, 1560-1576.

Aubert, O., Le Bars, M., Le Gal, P., Marcus, P. S., 2012. The universal aspect ratio of vortices in rotating stratified flows: experiments and observations. Journal of Fluid Mechanics 706, 34-45.

Barbosa Aguiar, A., Peliz, A., Cordeiro Pires, A., Le Cann, B., 2011. Zonal structure of the mean flow and eddies in the azores current system. Journal of Geophysical Research: Oceans $116(\mathrm{C} 2)$.

Barbosa Aguiar, A. C., Peliz, Á., Carton, X., 2013. A census of meddies in a long-term high-resolution simulation. Progress in Oceanography 116, 80-94.

Bashmachnikov, I., Boutov, D., Dias, J., 2013. Manifestation of two Meddies in altimetry and sea-surface temperature. Ocean Science 9, 249-259.

Bashmachnikov, I., Carton, X., 2012. Surface signature of Mediterranean water eddies in the Northeastern Atlantic: effect of the upper ocean stratification. Ocean Science 8 (6), 931-943.

Bashmachnikov, I., Carton, X., Belonenko, T., 2014. Characteristics of surface signatures of mediterranean water eddies. Journ. Geophys. Research: Oceans 119 (10), 7245-7266.

Bashmachnikov, I., Machín, F., Mendonça, A., Martins, A., 2009. In situ and remote sensing signature of meddies east of the mid-atlantic ridge. Journal of Geophysical Research: Oceans 114 (C5).

Bashmachnikov, I., Neves, F., Calheiros, T., Carton, X., 2015. Properties and pathways of mediterranean water eddies in the atlantic. Progress in Oceanography 137, 149-172.

Bower, A. S., Armi, L., Ambar, I., 1997. Lagrangian observations of meddy formation during a mediterranean undercurrent seeding experiment. Journal of Physical Oceanography 27 (12), 2545-2575.

Bower, A. S., Serra, N., Ambar, I., 2002. Structure of the mediterranean undercurrent and mediterranean water spreading around the southwestern iberian peninsula. Journal of Geophysical Research: Oceans 107 (C10). 
Carton, X., Chérubin, L., Paillet, J., Morel, Y., Serpette, A., Le Cann, B., 2002. Meddy coupling with a deep cyclone in the gulf of cadiz. Journal of Marine Systems 32 (1), $13-42$.

Carton, X., Daniault, N., Alves, J., Cherubin, L., Ambar, I., 2010. Meddy dynamics and interaction with neighboring eddies southwest of portugal: observations and modeling. Journal of Geophysical Research: Oceans 115 (C6).

Chelton, D., De Szoeke, R., Schlax, M., El Naggar, K., Siwertz, N., 1998. Geographical Variability of the Ffirst Baroclinic Rossby Radius of Deformation. Journal of Physical Oceanography 28, 433-459.

Chelton, D. B., Schlax, M. G., Samelson, R. M., de Szoeke, R. A., 2007. Global observations of large oceanic eddies. Geophysical Research Letters 34 (15).

Ciani, D., Carton, X., Bashmachnikov, I., Chapron, B., Perrot, X., 2015. Influence of deep vortices on the ocean surface. Interdiscip. j. discontin. nonlinearity complex. 4 (3), 281311.

Ciani, D., Carton, X., Verron, J., 2016. On the merger of subsurface isolated vortices. Geophysical \& Astrophysical Fluid Dynamics 110 (1), 23-49.

Colin de Verdière, A., 1992. On the southward motion of mediterranean salt lenses. Journal of physical oceanography $22(4), 413-420$.

Da Silva, A., Young, C., Levitus, S., 1994. Algorithms and procedures. vol. 1, atlas of surface marine data 1994. NOAA Atlas NESDIS 6, 83.

Dibarboure, G., Pujol, M.-I., Briol, F., Traon, P. L., Larnicol, G., Picot, N., Mertz, F., Ablain, M., 2011. Jason-2 in duacs: Updated system description, first tandem results and impact on processing and products. Marine Geodesy 34 (3-4), 214-241.

Dibarboure, G., Schaeffer, P., Escudier, P., Pujol, M.-I., Legeais, J.-F., Faugère, Y., Morrow, R., Willis, J., Lambin, J., Berthias, J., et al., 2012. Finding desirable orbit options for the extension of life phase of Jason-1. Marine Geodesy 35 (sup1), 363-399.

Fisher, R. A., et al., 1946. Statistical methods for research workers. Statistical methods for research workers. (10th. ed.).

Fu, L., Alsdorf, D., E., R., Morrow, R., Mognard, N., Lambin, J. ana Vaze, P., Lafon, T., 2009. The SWOT (Surface Water and Ocean Topography) mission: Spaceborne Radar Interferometry for Oceanographic and Hhydrological Applications. 
Fu, L.-L., Cazenave, A., 2000. Satellite altimetry and earth sciences: a handbook of techniques and applications. Vol. 69. Academic Press.

Gaultier, L., Ubelmann, C., Lee-Lueng, F., 2017. SWOT simulator documentation. Tech. rep.

Herbette, S., Morel, Y., Arhan, M., 2004. Subduction of a surface vortex under an outcropping front. Journal of physical oceanography 34 (7), 1610-1627.

Ienna, F., Jo, Y.-H., Yan, X.-H., 2014. A new method for tracking meddies by satellite altimetry. Journal of Atmospheric and Oceanic Technology 31 (6), 1434-1445.

Isern-Fontanet, J., García-Ladona, E., Font, J., 2003. Identification of marine eddies from altimetric maps. Journal of Atmospheric and Oceanic Technology 20 (5), 772-778.

Isern-Fontanet, J., Lapeyre, G., Klein, P., Chapron, B., Hecht, M. W., 2008. Threedimensional reconstruction of oceanic mesoscale currents from surface information. Journal of Geophysical Research: Oceans 113 (C9).

Jia, Y., 2000. Formation of an azores current due to mediterranean overflow in a modeling study of the north atlantic. Journal of Physical Oceanography 30 (9), 2342-2358.

Joyce, T. M., 1981. The influence of the mid-atlantic ridge upon the circulation and the properties of the mediterranean water southwest of the azores. Tech. rep., Woods Hole Oceanographic Institution.

Kase, R. H., Beckmann, A., Hinrichsen, H.-H., 1989. Observational evidence of salt lens formation in the Iberian Basin. Journal of Geophysical Research: Oceans 94 (C4), 49054912.

URL http://dx.doi.org/10.1029/JC094iC04p04905

Käse, R. H., Zenk, W., 1987. Reconstructed mediterranean salt lens trajectories. Journ. Phys. Oceanogr. 17 (1), 158-163.

Kida, S., Price, J. F., Yang, J., 2008. The upper-oceanic response to overflows: A mechanism for the azores current. Journal of Physical Oceanography 38 (4), 880-895.

Klein, B., Siedler, G., 1989. On the origin of the azores current. Journal of Geophysical Research: Oceans 94 (C5), 6159-6168.

Lapeyre, G., Klein, P., 2006. Dynamics of the upper oceanic layers in terms of surface quasigeostrophy theory. Journal of Geophysical Research 36 (2), 165-176. 
Lorbacher, K., Dommenget, D., Niiler, P., Köhl, A., 2006. Ocean mixed layer depth: A subsurface proxy of ocean-atmosphere variability. Journal of Geophysical Research: Oceans (1978-2012) 111 (C7).

Marchesiello, P., McWilliams, J. C., Shchepetkin, A., 2001. Open boundary conditions for long-term integration of regional oceanic models. Ocean modelling 3 (1), 1-20.

McDowell, S. E., Rossby, H. T., 1978. Mediterranean water: An intense mesoscale eddy off the bahamas. Science 202 (4372), 1085-1087.

Morel, Y., 1995. The influence of an upper thermocline current on intrathermocline eddies. Journal of physical oceanography 25 (12), 3247-3252.

Morel, Y., McWilliams, J., 1997. Evolution of isolated interior vortices in the ocean. Journal of Physical Oceanography 27 (5), 727-748.

Morrow, R., Birol, F., Griffin, D., Sudre, J., 2004. Divergent pathways of cyclonic and anti-cyclonic ocean eddies. Geophysical Research Letters 31 (24).

Nencioli, F., Changing, D., Dickey, T., Washburn, L., McWilliams, J., 2010. A VectorBased Eddy Detection Algorithm and Its Application to a High-Resolution Numerical Model Product and High-Frequency Radar Surface Velocities in the Southern California Bight. Journal of Atmospheric and Oceanic Technology 27, 564-579.

Okubo, A., 1970. Horizontal dispersion of floatable particles in the vicinity of velocity singularities such as convergences. In: Deep sea research and oceanographic abstracts. Vol. 17. Elsevier, pp. 445-454.

Oliveira, P. B., Serra, N., Fiúza, A. F., Ambar, I., 2000. A study of meddies using simultaneous in-situ and satellite observations. Elsevier Oceanography Series 63, 125-148.

Özgökmen, T. M., Chassignet, E. P., Rooth, C. G., 2001. On the connection between the mediterranean outflow and the azores current. Journal of Physical Oceanography 31 (2), 461-480.

Peliz, A., Boutov, D., Cardoso, R. M., Delgado, J., Soares, P. M., 2013. The gulf of cadizalboran sea sub-basin: Model setup, exchange and seasonal variability. Ocean Modelling $61,49-67$.

Peliz, A., Dubert, J., Marchesiello, P., Teles-Machado, A., 2007. Surface circulation in the gulf of cadiz: Model and mean flow structure. Journal of Geophysical Research: Oceans $112(\mathrm{C} 11)$. 
Pingree, R., Le Cann, B., 1993a. A shallow meddy (a smeddy) from the secondary mediterranean salinity maximum. Journal of Geophysical Research: Oceans (1978-2012) 98 (C11), 20169-20185.

Pingree, R., Le Cann, B., 1993b. Structure of a meddy (Bobby 92) southeast of the Azores. Deep Sea Research I 40 (10), 2077-2103.

Polvani, L., 1991. Two-layer geostrophic vortex dynamics, 2, alignment and two-layer vstates. Journal of Fluid Mechanics 225, 241-270.

Ponte, A., Klein, P., 2013. Reconstruction of the upper ocean 3d dynamics from highresolution sea surface height. Ocean Dynamics 63, 777-791.

Prater, M. D., Sanford, T. B., 1994. A meddy off cape st. vincent. part i: Description. Journal of Physical Oceanography 24 (7), 1572-1586.

Qiu-Yang, L., Sun, L., Sheng-Fu, L., 2016. Gem: a dynamic tracking model for mesoscale eddies in the ocean. Ocean Science 12 (6), 1249.

Richardson, P., Bower, A., Zenk, W., 2000a. A census of Meddies tracked by floats. Progress in Oceanography 45, 209-250.

Richardson, P., Bower, A., Zenk, W., 2000b. A census of Meddies tracked by floats. Progress in Oceanography 45 (2), 209-250.

Richardson, P., Price, J., Walsh, D., Armi, L., Schröder, M., 1989. Tracking three meddies with sofar floats. Journal of Physical Oceanography 19 (3), 371-383.

Richardson, P. L., Tychensky, A., 1998. Meddy trajectories in the canary basin measured during the semaphore experiment, 1993-1995. Journal of Geophysical Research: Oceans 103 (C11), 25029-25045.

Serra, N., Ambar, I., Boutov, D., 2010. Surface expression of mediterranean water dipoles and their contribution to the shelf/slope-open ocean exchange. Ocean Science 6 (1), $191-209$.

Shapiro, G., Meschanov, S., Emelianov, M., 1995. Mediterranean lens irving after its collision with seamounts. Oceanologica Acta 18 (3), 309-318.

Shchepetkin, A. F., McWilliams, J. C., 2005. The regional oceanic modeling system (ROMS): a split-explicit, free-surface, topography-following-coordinate oceanic model. Ocean Modelling 9 (4), 347-404. 
Stammer, D., Hinrichsen, H. H., Käse, R. H., 1991. Can Meddies be detected by satellite altimetry? Journal of Geophysical Research: Oceans 96 (C4), 7005-7014. URL http://dx.doi.org/10.1029/90JC02740

Stephens, J. C., Marshall, D. P., 1999. Dynamics of the mediterranean salinity tongue. Journal of physical oceanography 29 (7), 1425-1441.

Swallow, J., 1969. A deep eddy off cape st. vincent. Deep-Sea Res 16, 285-295.

Tychensky, A., Carton, X., 1998. Hydrological and dynamical characterization of meddies in the azores region: a paradigm for baroclinic vortex dynamics. Journal of Geophysical Research: Oceans 103 (C11), 25061-25079.

Vallis, G. K., 2006. Atmospheric and Oceanic Fluid Dynamics. Cambridge University Press, Cambridge, U.K.

Vic, C., Roullet, G., Capet, X., Carton, X., Molemaker, M. J., Gula, J., 2015. Eddytopography interactions and the fate of the persian gulf outflow. Journal of Geophysical Research: Oceans 120 (10), 6700-6717.

Volkov, D. L., Fu, L.-L., 2010. On the reasons for the formation and variability of the azores current. Journal of Physical Oceanography 40 (10), 2197-2220.

Weiss, J., 1991. The dynamics of enstrophy transfer in two-dimensional hydrodynamics. Physica D: Nonlinear Phenomena 48 (2-3), 273-294. 